PONTIFÍCIA UNIVERSIDADE CATÓLICA DO RIO DE JANEIRO

Estratégias de marketing no mercado gastronômico: um estudo sobre a inserção dos food trucks no mercado carioca

Eduardo Machado

Trabalho de Conclusão de Curso

Centro de ciências sociais - CCS

DEPARTAMENTO DE ADMINISTRAÇÃO

Graduação em Administração de Empresas 


\section{Eduardo Machado}

\section{Estratégias de marketing no mercado gastronômico: um estudo sobre a inserção dos food trucks no mercado \\ carioca}

Trabalho de Conclusão de Curso

Trabalho de Conclusão de Curso, apresentado ao programa de graduação em Administração da PUC-Rio como requisito parcial para a obtenção do titulo de graduação em Administração.

Orientador(a) : João Renato de Souza Coelho Benazzi 


\section{Agradecimentos}

Gostaria de agradecer o apoio de algumas pessoas que me ajudaram muito durante o decorrer deste estudo, seja me motivando, me ajudando a me concentrar para escrever ou apenas por existirem e preocuparem-se comigo. Posso assegurar que essas pessoas são muito especiais em minha vida, e que este agradecimento se refere não apenas ao apoio dado para a conclusão deste trabalho, como por todo o apoio em vida também.

Primeiramente gostaria de agradecer aos meus pais, Cristina e Daniel, pela educação que me deram, por meus estudos, por preocuparem-se comigo e me apoiarem incondicionalmente, sempre com muito amor e carinho.

Gostaria de agradecer ao meu irmão, Leonardo, por sempre me apoiar, incentivar e me ajudar a manter o foco, sempre me ajudando nas horas difíceis, tanto no decorrer do estudo quanto na vida.

À minha avó, Odette, e ao meu falecido avô Manoel, por terem sempre me incentivado na escolha do meu caminho profissional e por toda a experiência e exemplos de vida que puderam passar para mim. Aos meus falecidos avós paternos também, Diógenes e Antonieta, cujas histórias de vida me inspiram e motivam a continuar independente dos percalços.

Aos meus amigos Marcos, Lucas, Raphael, Alan, Matthias, Maísa, Marina e tantos outros, por todo o apoio, bons pensamentos e companheirismo que me deram, tanto durante a condução deste trabalho como em tantos outros momentos na vida.

Ao meu professor e orientador, João Benazzi, por ter me apoiado desde o início, me dando embasamento e norteando a execução deste trabalho, bem como a tantos outros professores da PUC-Rio e do Colégio Santo Inácio, cujos ensinamentos me prepararam ao longo da vida e me permitiram finalizar este estudo.

E finalmente, por que não ao meu cachorro, Hulk, por ser o maior companheiro de estudo e motivador, estando presente em cada momento da condução deste trabalho. 


\section{Resumo}

Machado, Eduardo. Estratégias de marketing no mercado gastronômico: um estudo sobre a inserção dos food trucks no mercado carioca. Rio de Janeiro, 2015. 58 p. Trabalho de Conclusão de Curso - Departamento de Administração. Pontifícia Universidade Católica do Rio de Janeiro.

O presente trabalho possui o objetivo de entender como está sendo implantado o conceito de food truck (uma nova modalidade de empreendimento no setor de gastronomia) no mercado carioca. O trabalho considerará tanto as estratégias de implantação do mercado no nível individual, analisando os cursos de ação de cada empreendedor para tornar este setor e seu empreendimento mais conhecidos, como também as estratégias conjuntas, organizadas na forma de associações, eventos e parcerias.

Para a investigação e análise das estratégias nos dois níveis (individual e conjunto), será feito um levantamento de dados através de uma pesquisa quantitativa, como forma de descobrir se as estratégias adotadas estão surtindo o efeito desejado, que seria fazer com que o consumidor-alvo tome conhecimento deste novo segmento do mercado gastronômico.

Palavras-chave

food truck, gastronomia, marketing, empreendedorismo

\section{Abstract}

Machado, Eduardo. Marketing strategies in the gastronomic market: a study on the integration of food trucks with the Rio de Janeiro market. Rio de Janeiro, 2015. 58 p. Trabalho de Conclusão de Curso - Departamento de Administração. Pontifícia Universidade Católica do Rio de Janeiro.

This work aims to understand how is the concept of food truck (a new type of enterprise in the food industry) been implemented in Rio de Janeiro's market. This work will consider both market deployment strategies at the individual level, analyzing the courses of action of each entrepreneur to make this sector and its enterprise better-known, as well as joint strategies, organized in the form of associations, events and partnerships.

For research and analysis of the strategies at both levels (individual and group), a data collection will be done through a quantitative research, as a way to find out if the strategies adopted are achieving their goal, which would be to 
cause the target consumer to become aware of this new segment of the food gastronomic market .

\section{Key-words}

food truck, gastronomy, marketing, entrepreneurship 


\section{Sumário}

1 O tema e o problema de estudo 1

1.1. Introdução ao tema e ao problema do estudo 1

1.2. Objetivo do estudo 2

1.3. Objetivos intermediários do estudo 2

1.4. Delimitação e foco do estudo 3

1.5. Justificativa e relevância do estudo 4

2 Revisão de literatura 5

2.1. Oceano azul: estratégias de marketing para novos mercados 5

2.1.1. Comparação com o caso Cirque du Soleil 6

2.2. O comportamento do consumidor brasileiro quanto à comida de rua 7

2.3. Marketing de serviços 9

3 Métodos e procedimentos de coleta e de análise de dados do estudo 16

3.1. Etapas de coleta de dados 16

3.2. Fontes de informação selecionadas para coleta de dados no estudo17

3.3. Procedimentos e instrumentos de coleta de dados utilizados no estudo

3.4. Formas de tratamento e análise dos dados coletados para o estudo 18

3.5. Limitações do Estudo

4 Apresentação e análise dos resultados 19

4.1. Sobre os food trucks 19

4.2. Descrição do perfil dos entrevistados 20

4.3. Descrição e análise dos resultados das entrevistas 22

4.4. Descrição do perfil da amostra 25

4.5. Descrição e análise dos resultados do questionário 27

5 Conclusões e recomendações para novos estudos 43

5.1. Sugestões e recomendações para novos estudos 46 


\section{Lista de figuras}

Figura 1: Porcentagem dos serviços no PNB. Fonte: Bateson e Hoffman (2001)

Figura 2: Diferenças básicas entre bens e serviços. Fonte: Lovelock e Wright (2002). 12

Figura 3: Food truck Cerveja Dead Dog. Fonte primária 20

Figura 4: Food truck Graviola. $\quad$ Fonte:
https://instagram.com/p/3On9LHO6Ky/?taken-by=graviolagourmet.......... 21 Figura 5: Food truck Roma in Rio. Fonte: https://www.facebook.com/romainriomassas/photos/pb.337854543030384.2207520000.1433831442./410181305797707/?type=3\&theater. 21

\section{Lista de Tabelas}

Tabela 1: Respostas da questão 8. 25

Tabela 2: Respostas da questão 9 ........................................................ 25

Tabela 3: Respostas da questão 10 ......................................................... 26

Tabela 4: Respostas da questão 1 .......................................................... 27

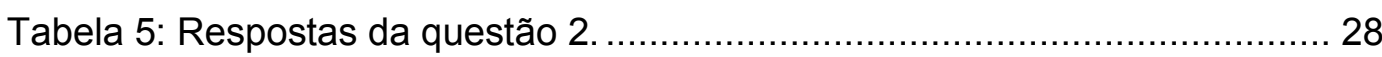

Tabela 6: Respostas do cruzamento entre as questões 1 e 2 ......................... 29

Tabela 7: Respostas da questão 3......................................................... 30

Tabela 8: Respostas da questão 4 ......................................................... 31

Tabela 9: Respostas do cruzamento entre as questões 3 e 4 ........................ 33

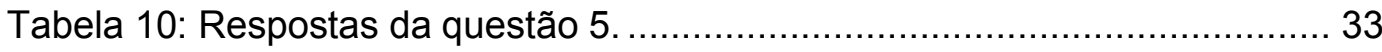

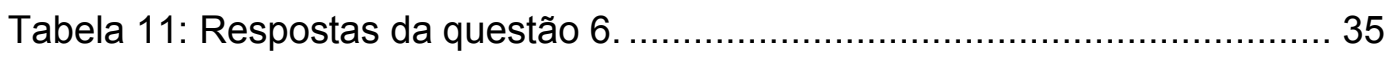


Tabela 12: Respostas da questão 7. 36

Tabela 13: Respostas do cruzamento entre as questões 4 e 8 ....................... 39

Tabela 14: Respostas do cruzamento entre as questões 4 e 9 ....................... 40

Tabela 15: Respostas do cruzamento entre as questões 4 e 10.................... 41

\section{Lista de gráficos}

Gráfico 1: Composição do PIB brasileiro. Fonte:Primária ................................ 10

Gráfico 2: Gráfico da questão 8. Fonte primária ............................................... 25

Gráfico 3: Gráfico da questão 9. Fonte primária ............................................ 26

Gráfico 4: Gráfico da questão 10. Fonte primária .......................................... 26

Gráfico 5: Gráfico da questão 1. Fonte primária ............................................ 28

Gráfico 6: Gráfico da questão 2. Fonte primária ........................................... 29

Gráfico 7: Gráfico da questão 3. Fonte primária ............................................. 30

Gráfico 8: Gráfico da questão 4. Fonte primária .............................................. 32

Gráfico 9: Gráfico da questão 5. Fonte primária ............................................... 34

Gráfico 10: Gráfico da questão 6. Fonte primária .......................................... 35

Gráfico 11: Gráfico da questão 7. Fonte primária ........................................ 37 


\section{0 tema e o problema de estudo}

Neste capítulo faremos uma introdução ao tema do estudo, aonde falaremos um pouco da história dos food trucks e de como o fenômeno está ocorrendo no Brasil. $\mathrm{Na}$ seção seguinte estabeleceremos os objetivos intermediários e o final, como forma de nortear o trabalho. Após informar os objetivos, informaremos a delimitação do estudo, e, por fim, para quais grupos este estudo poderia ter relevância.

\subsection{Introdução ao tema e ao problema do estudo}

Até bem pouco tempo atrás, o termo food truck provavelmente não fazia sentido para nenhum carioca, à menos que este tivesse ouvido o termo no exterior. Food truck, que traduzido do inglês quer dizer "caminhão de comida", ou "caminhão de alimentos", é a mais nova modalidade de empreendimento gastronômico no Rio de Janeiro e no Brasil. Embora o food truck ainda esteja incipiente no mercado carioca, em outras cidades brasileiras a população já está mais familiarizada com este segmento, sendo São Paulo a cidade aonde o fenômeno alcançou as maiores proporções, embora ainda não esteja de fato consolidado e ainda não haja legislação vigente.

Especula-se que os food trucks tenham nascido nos Estados Unidos, ainda no século XIX, sob a forma de pequenos carrinhos que vendiam comida barata e prática a operários saindo das fábricas, deste modo satisfazendo perfeitamente suas necessidades. Este modelo continuou sendo utilizado nos EUA e no mundo, sendo a característica desta versão do negócio o apelo de comida barata em qualquer lugar, sendo um exemplo de seu uso os "carrinhos" de pipoca e de cachorro quente, mundialmente conhecidos. Um novo modelo deste negócio, no entanto, foi criado nos EUA após a crise financeira de 2008. Por causa das dificuldades econômicas, muitos proprietários de restaurantes se viram à beira da falência, visto que os custos de se manter um estabelecimento fixo em uma cidade grande estava alto demais, enquanto que o consumo nos EUA estava muito baixo. A solução foi transformar veículos automotores em restaurantes móveis; porém, diferentemente do apelo antigo do negócio, desta vez o público-alvo seriam as classes mais altas. A inovação provou-se um 
sucesso, uma vez que os custos do empreendimento eram muito mais baixos do que comprar ou alugar um imóvel em uma cidade grande, além do fato de que esta diminuição nos custos pôde ser repassada aos consumidores através de preços de venda mais baixos também, desta forma agradando a todos e aumentando a visibilidade deste tipo de empreendimento em todo o mundo.

A novidade chegou ao Brasil ainda no ano 2014 e encontra-se em pleno desenvolvimento em diversas capitais, dentre elas São Paulo, Rio de Janeiro e Porto Alegre. Devido à falta de legislação sobre este tema nas cidades, por enquanto os food trucks não possuem permissão para vender nas ruas, sendo necessário alugar espaços privados na cidade para que elas possam ocorrer, sendo os locais mais visados os estacionamentos.

Levando-se em conta a grande repercussão provocada pelo nascimento deste segmento de mercado no Brasil e no mundo, chega-se à seguinte pergunta, que servirá para permear a condução deste trabalho: a forma como a inserção do mercado de food trucks está sendo feita está conseguindo atrair a atenção da população carioca?

\subsection{Objetivo do estudo}

O objetivo final deste trabalho é: analisar se a forma como a inserção do mercado de food trucks está sendo feita está conseguindo atrair a atenção da população carioca.

Este trabalho possui a finalidade de descobrir, analisar e avaliar as estratégias utilizadas para a inserção dos food trucks tanto pelas associações como pelos empreendedores individualmente, através de uma pesquisa junto aos potenciais consumidores, questionando-os sobre este mercado. O resultado deste trabalho, caso seja utilizado como feedback para os principais atores no nascimento deste mercado, poderá ser utilizado para revisar e aumentar a efetividade de suas estratégias.

\subsection{Objetivos intermediários do estudo}

Como forma de alcançar o objetivo final, deverão ser alcançados, primeiramente, três objetivos intermediários: 
- Identificar as estratégias de marketing utilizadas individualmente pelos empreendedores.

- Analisar as estratégias de marketing conjuntas utilizadas pelos envolvidos na inserção deste mercado no Rio de Janeiro

- Investigar e analisar o impacto junto ao público de consumidores em potencial

Os dois primeiros objetivos possuem a intenção de descobrir as estratégias de marketing utilizadas para tornar o mercado de food trucks conhecido entre o seu público-alvo, desta forma lentamente transformando-o no sucesso que este mercado representou nos outros países aonde foi introduzido. O primeiro objetivo consiste em identificar as estratégias de divulgação de cada empreendedor individualmente, como forma de descobrir se as causas do sucesso ou fracasso das estratégias se devem às estratégias conjuntas ou individuais.

O segundo objetivo intermediário busca analisar as estratégias conjuntas de marketing (executadas através de empresas de consultoria e agências de marketing) utilizadas para tornar este mercado conhecido, desta forma o estudo serve também para avaliar o grau de eficiência desta maneira de divulgar novos nichos de mercado (que seria o uso de empresas de consultoria/publicidade como forma de adotar uma estratégia única para a divulgação do novo mercado).

O terceiro objetivo intermediário possui a intenção de validar se as estratégias sendo utilizadas pelos envolvidos neste processo de "criação" do setor estão conseguindo atrair a intenção da população carioca, ou seja, se os meios de promoção estão sendo eficazes.

\subsection{Delimitação e foco do estudo}

Este estudo possui como delimitação a cidade do Rio de Janeiro, embora o processo de introdução do segmento de food trucks esteja ocorrendo quase que simultaneamente em diversas regiões do Brasil. Esta decisão está sendo tomada devido às restrições de pesquisa, que impossibilitariam a execução do estudo em escala nacional, visto que, para tanto, seria necessário produzir uma grande amostragem ou uma amostragem muito heterogênea.

Uma segunda delimitação deste estudo diz respeito à parcela dos food trucks que será analisada. Embora o segmento de food trucks possa envolver 
também os "carrinhos" de pipoca e cachorro quente anteriormente mencionados, bem como outras formas similares que busquem preparar alimentos na rua e vendê-los a baixo custo, neste estudo focaremos na parcela do mercado que possui como público-alvo o consumidor de renda mais elevada, visto que é esta a modalidade dos food trucks que está sendo introduzida no mercado carioca.

O foco do estudo estará concentrado no fenômeno dos food trucks no Rio de Janeiro, aonde tanto eventos de food truck quanto os empreendimentos individualmente estão tornando-se parte da cultura carioca. A intenção do estudo é a de descobrir se as ferramentas de divulgação estão conseguindo atingir seu público alvo, e caso esteja, se isto está de fato se concretizando em vendas nos eventos.

\subsection{Justificativa e relevância do estudo}

Este estudo pode representar uma significativa relevância para quatro públicos diferentes: empreendedores, chefs de cozinha, potenciais consumidores de food trucks e os próprios donos de food trucks.

Para empreendedores, este estudo pode estimular o investimento neste tipo de negócio, caso os objetivos intermediários e o final demonstrem uma resposta satisfatória quanto à tendência de crescimento da visibilidade dos food trucks perante o consumidor. Tanto as análises como a pesquisa em si podem representar idéias e pontos de vista interessantes para o potencial empreendedor, podendo inclusive auxiliá-lo na montagem do negócio.

Para os chefs de cozinha, a introdução dos food trucks pode representar uma alternativa de trabalho, um possível investimento ou até mesmo uma forma de divulgar sua comida, caso seja um chef renomado.

O terceiro grupo que poderia ser influenciado por este estudo seria o potencial consumidor de food trucks, pessoas que se identifiquem com esta novidade e passem a frequentar estes ambientes.

O último grupo para o qual este trabalho pode possuir relevância seria o dos próprios donos de food trucks, uma vez que este trabalho pode representar uma excelente forma de feedback sobre as ações que estão sendo realizadas, sejam estas as ações realizadas coletivamente com os outros donos de food trucks, ou as estratégias individuais. 


\section{Revisão de literatura}

Neste capítulo serão apresentados e discutidos aspectos conceituais e estudos relacionados ao tema, que servirão de base para a análise realizada. $O$ capítulo será dividido em três partes, divididas nos seguintes assuntos: o planejamento de marketing para novos mercados, também chamados de oceano azul; o comportamento do consumidor brasileiro quanto à comida de rua; e por fim discutiremos as estratégias de marketing para serviços.

\subsection{Oceano azul: estratégias de marketing para novos mercados}

Vivemos num mundo de competição empresarial muito acirrada, aonde é oferecida aos consumidores uma extensa gama de serviços e produtos, que por sua vez são comercializados tanto por empresas locais quanto por empresas de outras partes do mundo. Como forma de manter a competitividade contra tamanha concorrência, fazem-se necessárias políticas de redução de margens de lucro, maiores investimentos em tecnologia, diminuição da estrutura de custos e investimentos em marketing, uma vez que os produtos estão cada vez mais "commoditizados", ou seja, as diferenças determinantes entre os produtos baseiam-se cada vez mais nas marcas do que nas diferenças técnicas propriamente ditas.

Kim e Mauborgne (2005) chamam este fenômeno de "oceano vermelho", aonde a batalha pelo consumidor faz com que as empresas competindo em determinado setor comecem cada vez mais a competir por preços, uma vez que, tecnicamente, os produtos oferecidos são bastante semelhantes. Tal atitude acaba por provocar uma reação em cadeia, aonde cada empresa irá cada vez mais buscar a atenção do consumidor através da redução de preços, chegando ao ponto em que as próprias margens de lucro começam a ser reduzidas.

"Nos oceanos vermelhos, as fronteiras setoriais são definidas e aceitas, e as regras competitivas do jogo são conhecidas. Aqui, as empresas tentam superar suas rivais para abocanhar maior fatia da demanda existente. À medida que o espaço de mercado fica cada vez mais apinhado, as perspectivas de lucro e de crescimento ficam cada vez 
menores. Os produtos se transformam em commodities e a "briga de foice" ensanguenta as águas, dando origem aos oceanos." (Kim; Mauborgne, 2005, p.20)

Contrastando com o oceano vermelho, temos os oceanos azuis, que são mercados recém-criados e aonde não há concorrência, ou seja, não foram criados ainda padrões mercadológicos na indústria que possam "limitar" a lucratividade do setor. Ao tornar irrelevante a concorrência, torna-se possível atingir níveis de lucratividade mais altos do que as indústrias já existentes, tornando o risco de se aventurar em um novo mercado um fator de pouca relevância, quando analisadas as possibilidades de ganho por falta de restrições de lucratividade do setor.

"Os oceanos azuis, em contraste, se caracterizam por espaços de mercado inexplorados, pela criação de demanda e pelo crescimento altamente lucrativo." (Kim; Mauborgne, 2005, p.20)

\subsubsection{Comparação com o caso Cirque du Soleil}

Kim e Mauborgne (2005) relatam que um exemplo de oceano azul foi a criação do Cirque du Soleil. Segundo os autores, quando o circo foi criado, o mercado de circos estava decadente. Mesmo assim o empreendimento foi lançado, porém de uma forma completamente inovadora, com um modelo de negócios completamente diferenciado dos outros circos. As mudanças foram tão grandes, que a partir daí passou a considerar-se um mercado completamente novo. Por este motivo, pode-se considerar que o Cirque du Soleil não possuía concorrência, portanto encontrando-se em um "oceano azul".

O Cirque du Soleil nasceu em 1984, quando o mercado de circos estava decadente e a concorrência muito grande. As estratégias da indústria baseavamse, principalmente, na contratação de artista melhores, além do uso frequente de animais, sendo os melhores circos (com maior faturamento) os que possuíam os maiores custos também. Ao perceber que esse modelo de negócios estava falindo, o CEO do Cirque du Soleil, Guy Laliberté, entendeu que algumas das maiores características dos circos não estavam dando retorno, ao passo que estavam aumentando cada vez mais os custos dos negócios. O público cada vez mais se tornava intolerante ao uso de animais nos espetáculos, devido às condições de tratamento e encarceramento destes. Outro fator eram os artistas famosos, que apenas aumentavam os custos mas não representavam um aumento proporcional nas receitas, ou seja, eram supervalorizados pelos donos 
dos circos. Como forma de inovar no segmento, o Cirque de soleil optou por alterar comportamentos da indústria que nenhum concorrente havia questionado anteriormente. Os animais deixaram de ser utilizados, uma vez que o público não mais via o uso deles nos shows com bons olhos. Os artistas famosos também não seriam contratados, sendo o apelo do negócio o espetáculo em si, e não o uso de artistas para atrair os clientes. Por último, optou-se por visar públicos mais refinados ao adicionar à experiência do circo o uso de mais arte, combinando circo e teatro em um mesmo evento. Esta nova visão acabou por agregar valor ao espetáculo, permitindo com que os preços pudessem ser muito mais altos do que os dos concorrentes, ao passo em que o aumento de conforto nos espetáculos também agradava aos olhos das classes mais altas, que normalmente não mais se interessavam por esta indústria.

Aliando-se o aumento nos preços dos espetáculos com a diminuição de custos pelo corte de animais (que eram caros de se manter) e dos artistas famosos, obteve-se um modelo de negócios extremamente lucrativo, que não mais competia com os circos tradicionais, ou seja, não estava retirando fatias de mercado dos concorrentes, mas sim aumentando o bolo, desta forma trazendo benefícios, ao passo que criou-se uma nova indústria de entretenimento, que não mais era comparada com os circos, de tantas diferenças que haviam. O sucesso provou-se estrondoso, quase 40 milhões de pessoas já assistiram ao espetáculo, em 90 cidades ao redor do mundo. A lucratividade superou e muito à dos concorrentes, e em apenas 20 anos o Cirque du soleil alcançou o nível de receita que seus maiores concorrentes, Ringling Brothers e Bailey Circus, levaram 100 anos para alcançar.

\subsection{0 comportamento do consumidor brasileiro quanto à comida de rua}

De acordo com Maciel (2005), na alimentação humana, a dimensão biológica encontra-se com a cultural, uma vez que, apesar de o ato de alimentarse ser uma necessidade vital, outros fatores como com quem, quando e o que comer constituem-se em fatores sociais, que podem ajudar a dar um significado ao ato de se alimentar. Dentro da dimensão cultural, podemos ainda subdividir a alimentação em fatores de ordem ecológica, histórica, cultural, social e econômica, deste modo fazendo com que a alimentação passe a ser utilizada com caráter classificatório e de formação de identidade cultural. Podemos relacionar a criação desta identidade cultural ligada à alimentação ao conceito 
de "cozinha", aonde cada umas das diferentes "cozinhas" acaba por representar um laço cultural relacionado à alguma região, classe social ou etnia. De acordo com Maciel (2005), a cozinha de um grupo representa mais do que apenas o somatório de pratos típicos que identifiquem tal grupo, mas sim um misto de tradições e processos, que estão em constante mudança de acordo com o projeto coletivo do grupo participante desta identidade social.

Uma vez esclarecidas as diferenças entre alimentação pura e simples e a alimentação como um ato social, podemos agora tentar entender quais seriam as conexões destes conceitos com os diferentes tipos de comida de rua. De acordo com Pertile, Gastal e Guterres (2012), analisando historicamente, podemos perceber uma certa conotação pejorativa relacionada à rua, podendo citar como exemplos "mulher de rua", "festas de rua", "meninos de rua" e "comida de rua". Por trás destas associações podemos inferir que, por mais que se tente embutir um valor agregado à comida de rua, sempre existirá um certo receio, explicado principalmente por causa do preconceito com qualquer coisa relacionada à rua.

"Assim, para nós, modernos, que vivemos em sociedade onde a parte (o indivíduo) é mais importante que o todo (a sociedade), o problema estaria sempre no coletivo e na multidão." (DaMatta, 1997, p.43 apud Pertile; Gastal; Guterres, 2012, p.8)

Pertile, Gastal e Guterres (2012) estabelecem também uma contraposição entre a comida de casa e a comida de rua, aonde a comida caseira representa melhor uma identificação cultural do sujeito, aonde levam-se mais em conta fatores como cultura, fatores econômicos, gostos e disponibilidade de matéria prima, ao passo que a comida de rua é consumida levando-se em conta a proximidade ou a vontade do momento que "apeteça" mais os indivíduos, desta forma representando mais uma necessidade dos indivíduos (em grande parte explicada pelas distâncias entre casa e trabalho) do que uma identificação cultural ou seja, "Comer na rua pode ser mais rápido e prático do que ir para casa ou enfrentar filas em restaurantes" (PERTILE; GASTAL; GUTERRES, 2012, P.8). Percebe-se também que o ato de comer na rua denota pressa e praticidade, explicado por Garcia (1994 apud Pertile, Gastal e Guterres, 2012) como uma demanda do cotidiano, aonde o tempo mecânico suplanta a percepção do tempo percebido, desta forma fazendo com que a comida de rua nada mais seja do que uma forma de encurtar o tempo gasto com alimentação, como forma de utilizar o tempo com atividades produtivas no trabalho. Tal 
pensamento pode aproximar a comida de rua com o papel de alimentação como necessidade vital, contrapondo-se à visão de que seja uma identificação cultural do indivíduo.

Um importante fator relacionado à comida de rua é a questão do seu impacto na saúde de seus consumidores. De acordo com Tinker (1999), numa pesquisa realizada em diversos países, chegou-se à conclusão de que quanto menor e mais pobre é a família, maior é o percentual do orçamento alimentar gasto com comida de rua, o que seria um importante fator para entender a saúde nutricional de uma população. Embora não se saiba se os resultados da pesquisa seriam os mesmos no Brasil, a afirmação de que a composição da comida de rua pode interferir na saúde da população brasileira pode ser considerada, uma vez que, de acordo com Cardoso, Santos e Silva (2009), existe uma associação comprovada através de levantamentos em países da América Latina que correlaciona informalidade, menor renda e pior situação de saúde. A informalidade está amplamente conectada à comida de rua, uma vez que, em sua maior parte, a comida de rua é vendida não como uma opção, mas sim como forma de sustento para o empreendedor que, muitas vezes sem ter outras opções e com poucos recursos para manter os padrões mínimos de higiene da matéria prima e preparo do alimento vendido, acaba por tornar a comida de rua estigmatizada pelo público de classe mais alta, além de oferecer riscos à saúde quando mal preparada a comida.

\subsection{Marketing de serviços}

Vivemos num mundo onde serviços estão intrinsicamente relacionados à vida urbana, aonde estes são utilizados (entre outros motivos) como forma de nos ajudar a poupar tempo, um bem precioso neste meio agitado em que vivemos, aonde economia de tempo e eficiência são fundamentais para que se possa cumprir todos os nossos compromissos. Entre as facilidades que os serviços podem nos proporcionar, podemos citar uma série de atividades que, quando feitas através destes, podem nos economizar não apenas tempo, como também dinheiro, paciência, preocupação, entre muitos outros. $O$ mesmo pode ser aplicado às empresas, que muitas vezes recorrem a serviços executados por terceiros, uma vez que estes podem executar tal atividade (normalmente não correlata à atividade fim da empresa) com maior eficiência e eficácia, devido à ausência de know-how da empresa contratante sobre tal atividade. Pode-se utilizar como exemplo a utilização de profissionais de limpeza terceirizados, uma 
prática recorrente atualmente, uma vez que muitas vezes as empresas não possuem know-how ou mesmo interesse em despender tempo em aprender sobre tal atividade, implementar e organizar os processos relacionados e contratar e treinar pessoal para execução da limpeza.

Os serviços sempre estiveram presentes na vida do homem; porém, segundo Bateson e Hoffman (2001), foi após a Revolução Industrial que estes tiveram seu maior aumento de complexidade e diversidade, sendo o crescimento de dois serviços muito importantes - o ferroviário e o bancário - fundamental para que se pudesse realizar produção em larga escala. $O$ crescimento econômico advindo da Revolução Industrial, por sua vez, acabou por estimular o crescimento da indústria de serviços, já que com o aumento da prosperidade as pessoas passaram a poder dar-se o luxo de pagar por serviços que facilitassem suas vidas, muitas vezes comprando esses serviços como alternativa a realizar uma determinada atividade por conta própria, além de poder gastar mais dinheiro com atividades de lazer e diversão.

O setor de serviços, de acordo com Bateson e Hoffman (2001), constitui o grosso da economia brasileira, sendo responsável por $55 \%$ do Produto Interno Bruto (PIB). Tal tendência pode ser observada no resto do mundo também, tanto em países desenvolvidos quanto países em desenvolvimento. Nos Estados Unidos e no Canadá os serviços representam, respectivamente, $72 \%$ e $67 \%$ do Produto Nacional Bruto (PNB), por exemplo; na América Latina os serviços possuem uma participação um pouco menor, porém sempre com peso acima de $50 \%$ do PNB, e empregando a maior parte da força de trabalho (figura 2).

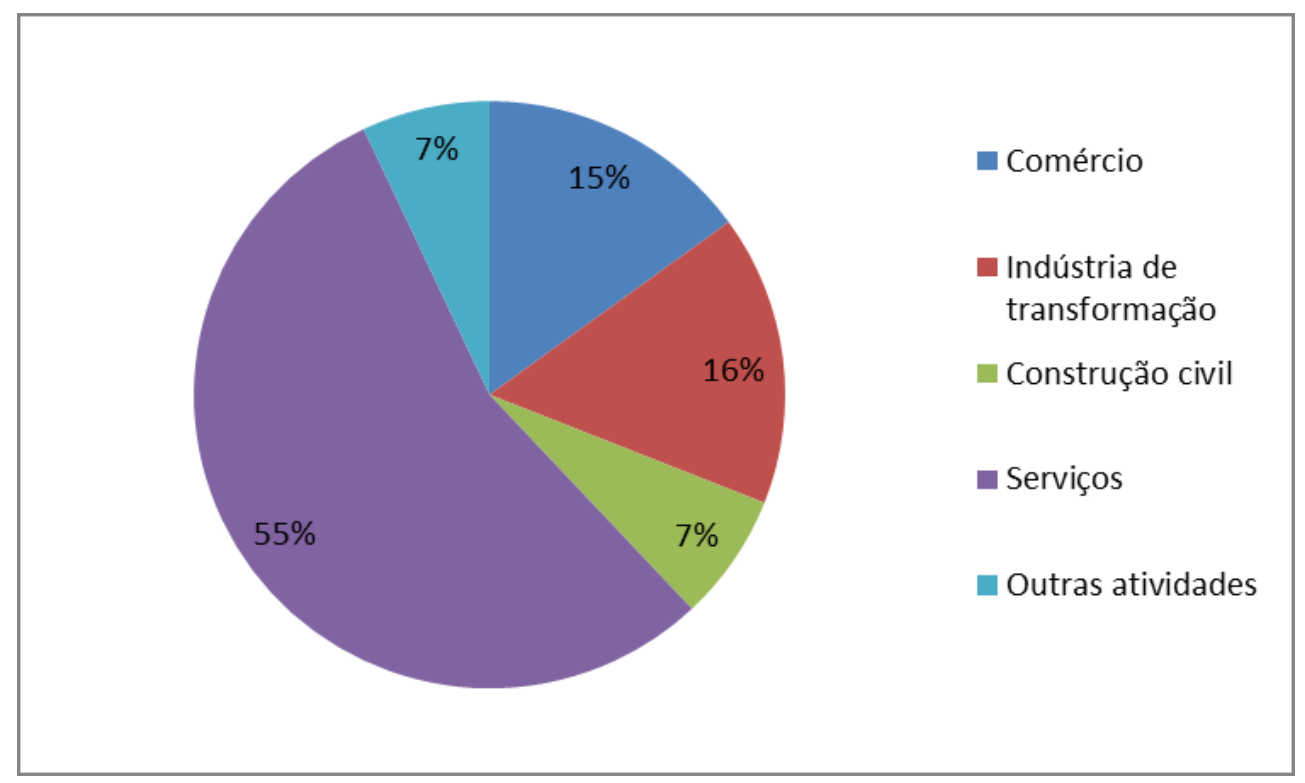

Gráfico 1: Composição do PIB brasileiro. Fonte:Primária 


\begin{tabular}{|c|c|c|c|c|}
\hline & & DISTRIBUIÇÃC & O DA FORÇA DE & TRABALBO \\
\hline Pats & $\begin{array}{l}\text { Porcentagem dos } \\
\text { Serviges no PNB }\end{array}$ & Agrialtura & Iodistria & Serviços \\
\hline Arosiling & 63 & 12 & 32 & 57 \\
\hline Breal & $5 \times 32$ & 22 & 23 & 53 \\
\hline Costa Ba & 39 & $25-3$ & -27 & 43 \\
\hline Repriblica Domitican & 62 & 24 & 18 & 58 \\
\hline Equeder & so & 31 & 18 & 51 \\
\hline Es Solador & 66 & II & 29 & 60 \\
\hline Gualengh & 55 & 50 & 18 & 32 \\
\hline Hondans: & 50 & $37>$ & 21 & 42 \\
\hline Hexse & 63 & 23 & 28 & 50 \\
\hline Panamí & 72 & 27 & 15 & 67 \\
\hline Pusto Rice & 57 & 4 & $26 \geq$ & 70 \\
\hline 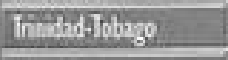 & 55 & 10 & 33 & 57 \\
\hline Uneysai & 64 & 15 & $5<26$ & 60 \\
\hline Kenzeda & 53 & 11 & $x=28$ & 61 \\
\hline
\end{tabular}

Figura 1: Porcentagem dos serviços no PNB. Fonte: Bateson e Hoffman (2001)

Devido à sua diversidade, existe uma grande dificuldade em conceituar serviço, sendo um complicador o fato de eles serem intangíveis, ou seja, por vezes pode ser difícil compreender o processo de criação e entrega dos serviços aos clientes. Lovelock e Wright (2002) conceituam serviços através de duas definições:

"Serviço é um ato ou desempenho oferecido por uma parte a outra. Embora o processo possa estar ligado a um produto físico, o desempenho é essencialmente intangível e normalmente não resulta em propriedade de nenhum dos fatores de produção." (Wright; Lovelock, 2002, p.5)

"Serviços são atividades econômicas que criam valor e fornecem benefícios para clientes em tempos e lugares específicos, como decorrência da realização de uma mudança desejada no - ou em nome do - destinatário do serviço." (Wright; Lovelock, 2002, p.5)

Para que possamos falar do marketing, devemos antes explicar as principais diferenças entre o marketing de serviços e o de bens físicos. Para tanto, devemos antes definir a diferença básica entre bens e serviços, sendo os bens objetos ou dispositivos físicos, enquanto que os serviços são ações ou desempenhos. Outras pesquisas indicaram as principais diferenças nos serviços como sendo a intangibilidade, a heterogeneidade, a perecibilidade do resultado e simultaneidade entre produção e consumo (SASSER; OLSEN; WYCKOFF, 1978 
apud WRIGHT; LOVELOCK, 2002). Um estudo mais recente amplia esta diferença para nove diferenças básicas, descritas na figura 3:

on clientes nio obthm propriedude sobre os servigos

os produtos dos serviços sio ralizaços intangivels

hit mior omolvimento dos ellentes no processo de productio

cutans pessoas podem farer purte do produto

hat maior variabl tade nos insumos e produtos cperacionals

multos yervicos t5o de diffeil aralaplo pelos clicntes

nommalmente hit urna austncia de estoques

o fator tempo if relativamente mas importante

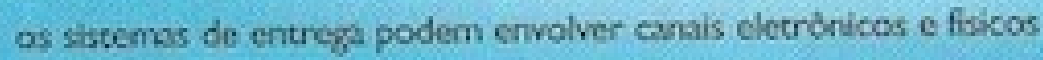

Figura 2: Diferenças básicas entre bens e serviços. Fonte: Lovelock e Wright (2002)

Vemos que existem diferenças importantes entre produtos e serviços, e, portanto, as estratégias de marketing devem ser diferentes, como forma de adaptar-se às características únicas dos serviços. Na estratégia de marketing de produtos, aprendemos sobre os 4 "ps" do mix de marketing (KOTLER,1996), preço, praça, produto e promoção, como sendo peças fundamentais para uma boa gestão das políticas de marketing. No entanto, ao adaptar esse conceito aos serviços, Lovelock e Wright (2002) criaram o modelo dos 8 "ps", sendo estes derivados das palavras em inglês: product elements, place and time, process, productivity and quality, people, promotion and education, physical evidence, price and other costs of service.

De acordo com Lovelock e Wright (2002), o elemento product elements (elementos do produto) é definido basicamente como sendo uma derivação do "produto" do composto de marketing original, sendo, no entanto, feita uma adaptação que acrescenta ao seu conceito também os elementos que suplementam o produto ou serviço principal, levando-se em conta benefícios desejados pelos clientes e o grau de desempenho dos produtos concorrentes.

O termo place and time (lugar e tempo) refere-se ao elemento praça do composto original, porém complementando-o com o fator tempo, que, no caso dos serviços, acaba por influenciar diretamente o consumidor, normalmente influenciados pela distribuição e entrega do produto ou serviço (a demora na entrega por vezes pode custar a fidelização de um cliente).

O elemento process (processo) refere-se à necessidade de implementação de processos eficazes para que sejam criados e entregues os elementos do produto ao cliente de forma satisfatória, da mesma forma em que processos mal 
formulados podem acabar por resultar em um mal desempenho na linha de frente, podendo ocasionar em baixa produtividade e aumentar a probabilidade de que ocorram falhas nos serviços.

O elemento productivity and quality (produtividade e qualidade) é composto de dois termos que à princípio podem ser abordados de forma diferente, mas que devem ser vistos como antagônicos e complementares ao mesmo tempo. Ao mesmo tempo em que a produtividade é essencial para manter os custos sobre controle, é necessário também tomar cuidado para que a redução indiscriminada de custos não afete a qualidade do serviço, interferindo assim na percepção do cliente.

People (pessoas) é o elemento do composto que estabelece que a interação entre o funcionário e o consumidor é essencial para que o cliente possua uma boa percepção sobre a qualidade do serviço, tomando como base para este pensamento a ideia de que a avaliação do serviço pelo cliente é, muitas vezes, influenciado na maior parte pelo contato que elas tiveram com as pessoas que fornecem os serviços.

Promotion and education (promoção e educação) é o elemento do composto que desempenha o papel de realizar não apenas a promoção, parte do elemento tradicional do mix de marketing, como também a educação do cliente, que no caso seria "ensinar" o cliente como o serviço deve ser utilizado, visto que muitas vezes estes precisam ser aprendidos, sendo para este meio utilizados tanto os meios de comunicação tradicionais, como também através de vendedores e treinadores, que devem ensinar ao cliente os benefícios do serviço, os processos inerentes à utilização deste e onde e quando obtê-lo.

Physical evidence (evidência física) refere-se aos aspectos da imagem que é passada ao consumidor pelo lugar aonde o serviço é prestado ao cliente, ou aonde o cliente possui algum contato físico com as prestadoras do serviço. Este elemento serve como forma de tangibilizar o serviço, sendo essenciais para isso a decoração, aparência dos edifícios, jardins, veículos e até mesmo o slogan da empresa.

O último elemento, price and other costs of service (preço e outros custos de serviço), relacionado ao elemento "preço" do mix de marketing tradicional, é complementado pelos custos que podem acompanhar o preço principal do serviço, que muitas vezes podem influenciar negativamente a percepção do consumidor, mesmo que às vezes estes custos não sejam necessariamente custos do produto em si, sendo levados em conta também custos não materiais, 
tais como cansaço, dificuldade de aprender sobre o serviço, tempo e experiências sensoriais negativas.

Podemos dizer que o consumidor é a peça mais importante de uma empresa, uma vez que sem eles nenhuma empresa sobrevive ou até mesmo possui sentido. É papel do profissional de marketing entender os consumidores e a partir deste entendimento desenvolver a organização em função deles, através de estratégias de marketing. Tal entendimento, segundo Bateson e Hoffman (2001), é particularmente mais importante no caso dos serviços, que no passado tenderam a ser dominados por operações, e não por marketing. Esta visão, no entanto, acabou por ser superada pelo entendimento de que é peça fundamental do sucesso entender como os consumidores escolhem os serviços alternativos que lhes são oferecidos e como eles avaliam estes após recebê-los.

"Entender a ligação entre processos de escolha e avaliação é particularmente importante, já que consumidores satisfeitos são necessários para a repetição dos negócios." (Bateson; Hoffman, 2001, p 48)

Como forma de entender o comportamento de consumidores de serviços, podemos utilizar o modelo de três estágios de comportamento do consumidor de serviços, de Bateson e Hoffman (2001), que é dividido nas seguintes fases: o estágio pré-compra, o estágio do consumo e a avaliação pós-compra.

O estágio pré-compra é a fase relacionada à todas as atividades que precedem a compra do serviço, como forma de entender o porquê de um determinado consumidor ter decidido utilizar um serviço, ou seja, descobrir quais fatores foram determinantes para a escolha de um serviço ou lugar onde se presta serviços. Entre os fatores que influenciam o processo decisório para a compra de um serviço, podemos citar a ocasião que leva um consumidor a optar por determinado serviço, o lugar, suas motivações e outras muitas variáveis, que por sua vez são influenciadas por informações internas e externas ao consumidor, que por fim acabam por solucionar o "problema" deste, que será solucionado por meio da aquisição do serviço. Bateson e Hoffman (2001) argumentam que a base da tomada de decisão do consumo é influenciada por uma quantidade limitada de opções, que por sua vez são influenciadas por experiências passadas, conveniência e conhecimento, sendo esta lista chamada de "conjunto evocado", que são as marcas lembradas pelo consumidor e que serão levadas em conta na escolha da compra.

O próximo estágio, o "estágio do consumo" é consequência direta da parte final do primeiro estágio, que seria a decisão de escolha por uma marca ou 
serviço. Esta decisão, por sua vez, vem acompanhada de expectativas do consumidor quanto ao desempenho do produto ou serviço, sendo estas expectativas satisfeitas ou não após o processo da compra. Vale lembrar que a identificação por parte dos gestores de o porquê de certo produto ter atendido ou não às expectativas do cliente é mais facilmente identificável na venda de bens físicos do que no de serviços, uma vez que o último possui a característica de misturar a compra do produto, o uso e o descarte deste em um mesmo momento (agrupados no estágio de consumo neste modelo). Já para os bens, os processos de compra, uso (consumo) e descarte são realizados em diferentes momentos, portanto não podendo ser analisados da mesma forma do que na venda de serviços. Esta peculiaridade dos serviços faz com que não apenas a identificação das razões de satisfação/insatisfação do cliente seja mais complexa, como também a torna intrinsicamente relacionada ao processo interativo entre prestador de serviço e consumidor, sendo a "solução do problema" do cliente apenas um dos elementos na equação da satisfação deles. Mesmo quando a prestação de serviços ocorre quando relacionada a um objeto físico e não à pessoa propriamente dita, a interação entre o cliente e o prestador pode ser decisiva para o julgamento do cliente quanto ao serviço.

Bateson e Hoffman (2001) salientam que esta maior "interface cliente/empresa" é proveniente de uma particularidade do consumo de serviços: o fato de a produção e o consumo ocorrerem simultaneamente, fazendo com que alguns autores considerem que a fase de avaliação pós-escolha aconteça tanto durante quanto após o consumo do serviço, e não apenas após o consumo deste.

No estágio de "avaliação pós-compra" chega-se ao resultado final pretendido pelo processo de marketing: descobrir qual é a opinião dos clientes com relação ao serviço. Tal pergunta possui importância estratégica para o gestor de marketing, uma vez que a não satisfação do cliente pode não apenas afastar a possibilidade de que ele volte a contratar este serviço, como também pode influenciar negativamente a imagem da marca por outras pessoas, à medida em que o cliente, através do boca a boca, dissemina sua insatisfação com relação ao serviço ou marca. O nível de complexidade na avaliação dos serviços é também interligado à subjetividade da avaliação de cada cliente, uma vez que cada cliente possui tanto expectativas diferentes com relação ao produto, como também possuem percepções diferentes sobre como um mesmo serviço foi entregue. 


\section{Métodos e procedimentos de coleta e de análise de dados do estudo}

Este capítulo pretende informar sobre as diversas decisões à cerca da forma como este estudo foi realizado.

Está dividido em cinco seções que informam, respectivamente, sobre as etapas de coleta de dados do estudo realizado; sobre as fontes de informação selecionadas para coleta de informações neste estudo; os processos e instrumentos de coleta de dados realizados em cada etapa, com respectivas justificativas sobre as formas escolhidas para tratar e analisar os dados coletados; e, por fim, sobre as possíveis repercussões que as decisões sobre como realizar o estudo impuseram aos resultados obtidos.

\subsection{Etapas de coleta de dados}

Este trabalho pretendia, inicialmente, contar com três etapas complementares de pesquisa, duas qualitativas e uma quantitativa, porém uma das etapas não pode ser realizada pois não houve retorno por parte dos potenciais entrevistados. Houve, então, uma adaptação para que se pudesse colher as informações necessárias através da segunda pesquisa qualitativa. A primeira parte é composta de entrevistas com três donos de food trucks, como forma de buscar compreender quais estão sendo suas estratégias de marketing individualmente, além de entender como os empreendedores individualmente se conectam com a estratégia coletiva dos envolvidos na introdução deste mercado no Rio de Janeiro. A segunda parte, a que não pôde ser realizada, seria composta de outra entrevista, desta vez com a empresa responsável por representar todos os envolvidos na introdução e criação deste novo mercado. $O$ objetivo desta pesquisa exploratória era buscar entender quais são as estratégias utilizadas por esta empresa, além de compreender quais foram as forças externas responsáveis pelo desenvolvimento deste mercado no Rio de Janeiro. A terceira e última etapa consiste de um questionário estruturado que visa descobrir a efetividade das estratégias de divulgação dos eventos e dos food trucks individualmente. A pesquisa visa descobrir se as estratégias individuais e conjuntas no mercado estão cumprindo seus objetivos, que seriam 
o de tornar esta novidade mais conhecida, além de chamar clientes para os eventos.

Como forma de adaptar-se à falta de uma das partes da pesquisa, as informações pretendidas foram buscadas na primeira parte da pesquisa, aonde buscou-se esclarecer com os donos de food trucks as informações que teriam sido concedidas pela empresa de eventos.

\subsection{Fontes de informação selecionadas para coleta de dados no estudo}

Na primeira etapa do estudo, foram entrevistados três donos de food truck, uma vez que estes estão envolvidos diretamente em todo o processo de introdução do mercado, além de participarem ativamente deste processo. A segunda etapa, como explicada na seção anterior, seria composta de uma entrevista com um gerente da empresa responsável pela estratégia conjunta de marketing dos food trucks no Rio de Janeiro, uma vez que seria necessário um cargo tático/estratégico para compreender e expressar corretamente 0 desenvolvimento e planejamento dos acontecimentos. As informações que seriam cedidas pelo gestor desta empresa foram então buscadas nas entrevistas com os donos de food trucks. Na terceira etapa, foi feito um questionário, como forma de descobrir se as estratégias de divulgação estão surtindo efeito, sendo necessário para a realização desta etapa uma amostragem com número maior ou igual a cem. A amostra foi escolhida por acessibilidade, uma vez que o questionário foi feito através da ferramenta qualtrics e divulgado através de redes sociais e por email. Nesta última etapa visa-se descobrir se o público-alvo dos food trucks está sendo atingido pelos esforços de marketing dos envolvidos na introdução deste mercado, além de descobrir quem seria o público-alvo através do questionário estruturado.

\subsection{Procedimentos e instrumentos de coleta de dados utilizados no estudo}

$\mathrm{Na}$ primeira etapa do estudo, foi realizada uma pesquisa exploratória qualitativa na forma de uma entrevista com os donos de food trucks, uma vez que este método dá mais liberdade para que os pesquisados opinem e discorram livremente sobre o tema. A segunda etapa, como informado na seção anterior, consiste de um questionário com uma amostra de 100 pessoas ou mais, visando descobrir a efetividade da campanha de marketing. 


\subsection{Formas de tratamento e análise dos dados coletados para o estudo}

Na primeira etapa do estudo, as entrevistas realizadas foram gravadas e transcritas para computador. Após este processo, usou-se análise de conteúdo das respostas no tratamento e análise dessa etapa de pesquisa. Na segunda etapa, o questionário estruturado foi realizado utilizando-se questões de múltipla escolha e de escala likert, ao passo que as respostas foram analisadas através de análise de frequência e de tabulação cruzada, como forma de entender se a estratégia de divulgação está cumprindo com o objetivo de tornar este novo mercado conhecido e atrair clientes para os eventos ao mesmo tempo.

\subsection{Limitações do Estudo}

Este estudo apresenta duas limitações relacionadas às pesquisas realizadas: a primeira consiste na possibilidade de que, durante a primeira etapa (entrevista com donos de food trucks), estes dêem suas respostas com "viés de vendas", ou seja, procurem exaltar os pontos positivos do ramo e omitir os negativos, como forma de utilizar a pesquisa para retratar este negócio como positivo, e assim cativar os leitores deste estudo, transformando-os em prováveis consumidores deste mercado.

A segunda limitação do estudo diz respeito à possibilidade de viés na terceira etapa (questionário com público-alvo), uma vez que existe a possibilidade de que a pesquisa seja enviesada devido ao desconhecimento de uma grande parcela do público-alvo nesta fase introdutória. O risco de viés aconteceria caso estas pessoas que desconhecem o mercado respondessem que o conhecem, seja por achar que serão julgadas, por achar que receberão benefícios ou até mesmo pelo simples ato de querer agradar. Apesar de ambas as limitações constituírem-se como possíveis de acontecer, são partes importantes do estudo, sendo elas integradas diretamente com os objetivos do estudo, e, desta forma, insubstituíveis. 


\section{Apresentação e análise dos resultados}

Este capítulo, organizado em cinco seções apresenta e discute os principais resultados alcançados, além dos métodos utilizados para que estes sejam analisados.

A primeira seção consiste de uma visão geral sobre o fenômeno dos food trucks e como está acontecendo a introdução deste novo segmento de mercado na cidade do Rio de Janeiro. A seguir trataremos da descrição dos entrevistados, seguida, na seção seguinte, da análise desta etapa da coleta de dados.

$\mathrm{Na}$ quarta seção trataremos da descrição do perfil da amostra coletada através do questionário.

Por fim, na quinta e última seção analisaremos as respostas coletadas do questionário.

\subsection{Sobre os food trucks}

O mercado de food trucks encontra-se em plena ascensão no Rio de Janeiro, sendo este novo mercado um fenômeno iniciado em 2014, seguindo o exemplo de outros países, e que está caminhando para tornar-se parte da cultura carioca. O fenômeno acabou por ganhar impulso através de uma estratégia utilizada pelos donos de food truck de reunir-se em "feiras" ou "eventos", realizadas com o intuito de torná-los mais conhecidos para o público, antes que fossem legalizados e regulamentados os meios utilizados pelos food trucks para comercializar em espaços públicos. Até que esta atividade fosse regulamentada pela prefeitura e pela Assembléia do Rio de Janeiro, estes eventos foram e estão sendo realizados em espaços privados, como forma de superar esta carência de regulamentação da atividade para espaços públicos. Tal estratégia acabou por provar-se um método eficaz não só pelo fato de atrair tanto curiosos como clientes dos food trucks, mas também como forma de diferenciá-los dos restaurantes (seus concorrentes diretos), uma vez que, pelo fato de esses eventos serem realizados em locais diferentes e em datas diferentes, estes acabam por não tornarem-se parte da rotina dos frequentadores, mas sim de atrações feitas para serem aproveitadas mais como 
forma de lazer do que com o objetivo de saciar a necessidade biológica de alimentação dos frequentadores.

\subsection{Descrição do perfil dos entrevistados}

O perfil da amostra dos entrevistados nesta primeira etapa da coleta de dados consistiu de três donos de food truck, de faixas de idade variadas, sendo estas entrevistas realizadas durante o evento "moda carioca" realizado no Museu Militar Conde de Linhares, em São Cristovão, no dia 24/05/2015. O evento consistiu de um misto entre uma feira de food trucks e de roupas e artigos para vestuário.

A seguir serão listadas as informações dos três entrevistados, informações estas que foram autorizadas a ser divulgadas pelos respondentes. Como forma de facilitar a leitura, nas próximas seções os respondentes serão referidos como respondentes 1,2 e 3 , de acordo com a ordem da listagem de seus dados abaixo, ao invés de serem referidos através de seus nomes.

Respondente 1:

Nome: Sandro

Nome do empreendimento: Cerveja Dead Dog

Especialidade gastronômica do food truck: cerveja artesanal de marca própria

Data em que adquiriu o food truck: setembro/2014

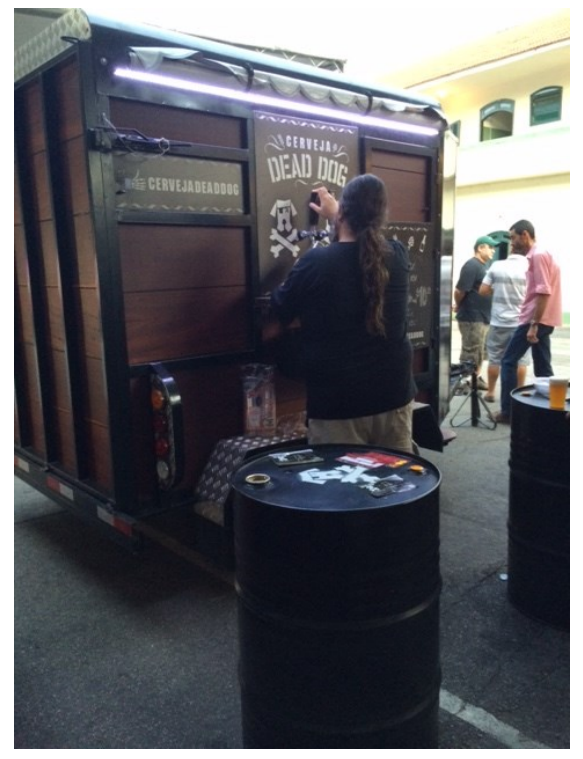

Figura 3: Food truck Cerveja Dead Dog. Fonte primária

Respondente 2:

Nome: Manoela

Nome do empreendimento: Graviola 
Especialidade gastronômica do food truck: comida natural

Data em que adquiriu o food truck: dezembro/2014

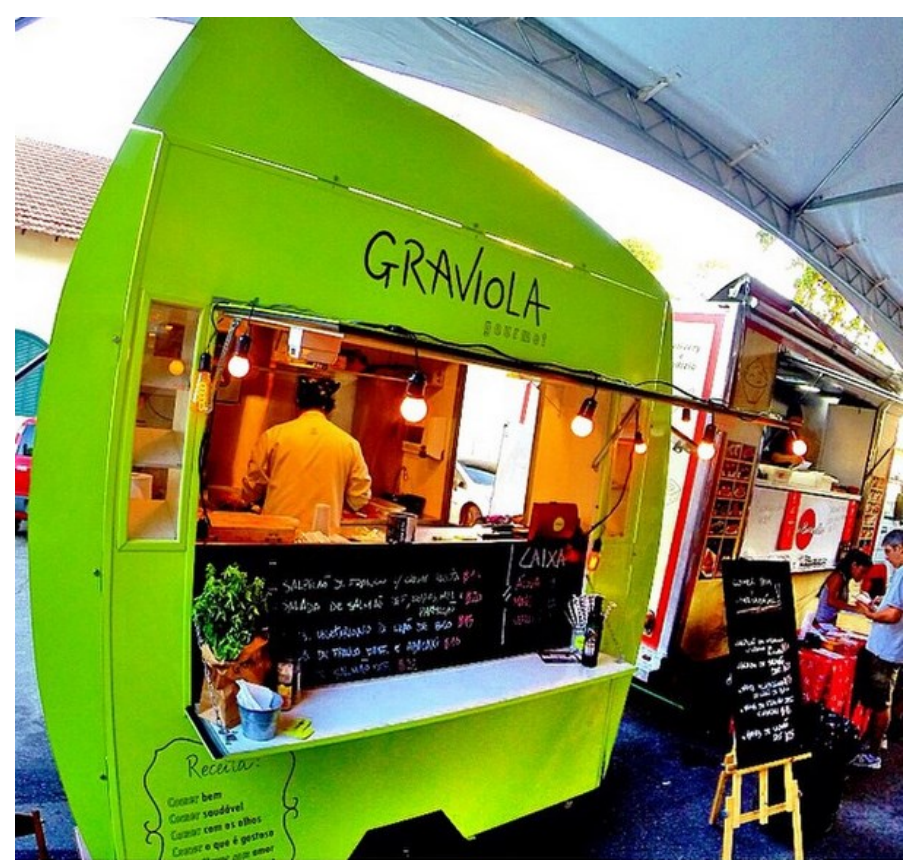

Figura 4: Food truck Graviola. Fonte: https://instagram.com/p/3On9LHO6Ky/?takenby=graviolagourmet

Respondente 3:

Nome: Jairo

Nome do empreendimento: Roma in Rio

Especialidade gastronômica do food truck: comida italiana

Data em que adquiriu o food truck: julho/2014

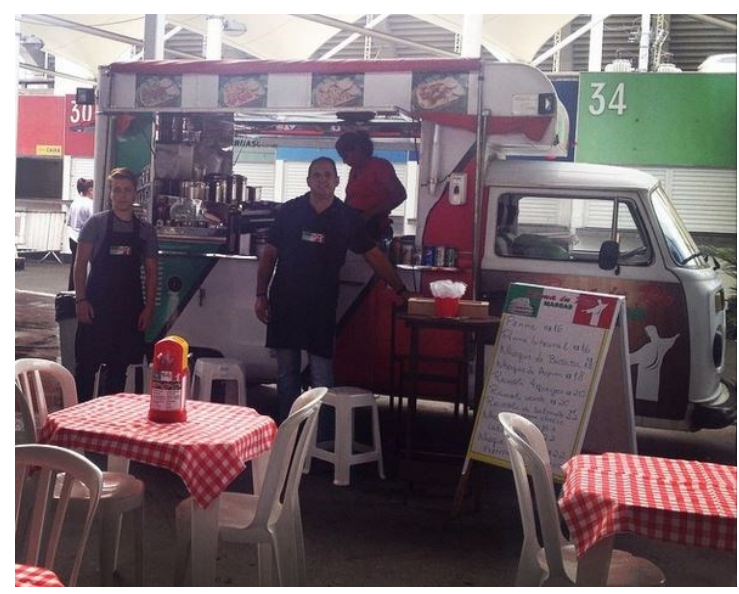

Figura 5: Food truck Roma in Rio. Fonte:

https://www.facebook.com/romainriomassas/photos/pb.337854543030384.-

$2207520000.1433831442 . / 410181305797707 /$ ?type=3\&theater 


\subsection{Descrição e análise dos resultados das entrevistas}

Para a realização da entrevista foram elaboradas oito perguntas, sendo quatro relacionadas aos meios de divulgação tanto dos empreendedores individualmente quanto dos eventos, e as outras quatro relacionadas ao perfil dos entrevistados e de seus negócios, tendo sido descritas na seção 4.2.

A primeira pergunta foi "Como foi a sua ideia de montar o food truck? Você já trabalhava no ramo gastronômico antes?".

O objetivo da pergunta foi o de descobrir o grau de experiência dos empreendedores no ramo, além de descobrir se o fato de a tendência de o fenômeno dos food trucks ser um novo mercado (oceano azul) foi um motivo para que mesmo empreendedores sem experiência no ramo se aventurassem nele. De acordo com Kim e Maubogne (2005), a diferença básica entre oceano azul e vermelho é a de que, pelo fato de existirem nos "oceanos vermelhos" as barreiras de lucratividade (criadas pela política de preços e margens de lucro da concorrência), o setor acaba sendo menos chamativo para novos empreendedores, porém assim que um setor de mercado é criado, a ausência dessas barreiras de lucratividade desse "oceano azul" acaba por atrair investidores para o mercado, muitas vezes criando o negócio sem experiência no ramo. As respostas transcritas dos respondentes foram as seguintes:

Respondente 1: "Nós tivemos a ideia de vender a cerveja, que é uma receita nossa, e esta foi a maneira que nós achamos mais legal de vender a cerveja e de divulgar a marca, aproveitando essa onda de food trucks. Mas possuímos apenas o beer truck, como o chamamos, não tivemos nenhum empreendimento gastronômico antes.

Respondente 2: "Na verdade meu noivo é formado em gastronomia e veio para o Rio para trabalhar em alguma coisa que não fosse tão fixa, pois nós gostamos muito de viajar. Nós tivemos a ideia de montar o food truck, e escolhemos comida natural pois é o que nós mais gostamos, mas nós nunca tivemos nenhum restaurante antes."

Respondente 3: "Minha área é totalmente diferente, mas eu sempre gostei muito de cozinhar e comida italiana é uma coisa que eu gosto, então decidi fazer. Mas nunca tive um empreendimento gastronômico antes."

De acordo com as respostas, pode-se perceber que, pelo menos analisando à partir desta amostra, grande parte dos empreendedores está iniciando seu primeiro empreendimento gastronômico, podendo ser esta uma evidência de que o mercado de food trucks pode ser considerado como um 
oceano azul (KIM;MAUBOGNE,2005), uma vez que, como mencionado anteriormente, a ausência de barreiras de lucratividade do setor pode atrair muitos investidores e empreendedores, inclusive os que não possuem experiência no ramo.

A segunda pergunta foi relacionada às estratégias de divulgação utilizadas individualmente pelos empreendedores: "Quais são as estratégias utilizadas para a divulgação do seu empreendimento?".

Respondente 1: "Eu utilizo apenas as redes sociais para alcançar meus clientes, ou seja, facebook, twitter, instagram."

Respondente 2: "Principalmente instagram, mas temos site, facebook, parcerias com outros food trucks, além de patrocínio de atletas."

Respondente 3: "Basicamente apenas as redes sociais, facebook, instagram, além do grosso da divulgação, que é feito pelos eventos."

A partir destas respostas pode-se perceber que, à exceção da respondente 2 , os respondentes limitam-se mais às redes sociais, ao passo que a maior parte dos esforços de divulgação ficam a cargo dos eventos. A respondente 2, por sua vez, parece optar por fortalecer a marca de seu próprio food truck, como forma de atrair não apenas uma maior quantidade de clientes nos eventos, como tornar seu truck mais conhecido entre os planejadores dos eventos, aumentando assim a visibilidade para seus futuros clientes, para quando houver legislação para se estabelecer em espaços públicos.

A terceira pergunta refere-se às origens dos eventos: "Quando começaram os eventos? De quem foi a ideia de começar a realizá-los?".

Respondente 1: "Bom, essa foi uma tendência que foi crescendo, foi passando a ser viável, por que na verdade o conceito de food truck já existia, ele foi apenas modificado, "goumetizado" como dizem. Mas na verdade são vários grupos que organizam estes eventos, e alguns deles estão crescendo e se fechando, criando uma organização maior. Agora existe inclusive uma associação de comida sobre rodas que está sendo criada, que vai se tornar mais um grupo desses."

Respondente 2: "Bom, o primeiro food truck foi feito há dois anos, e se chama nomad truck, mas esse boom de eventos começou em setembro de 2014, sendo que o primeiro evento foi no Village Mall, e hoje já existe também uma associação para os food trucks. Mas eu acredito que não foi apenas uma pessoa ou empresa, foi mais a globalização, pois isso começou em Nova York, foi para São Paulo e depois cresceu para o Brasil todo, e agora o Rio, então 
acredito que seja mais um inconsciente coletivo mesmo, eu acredito que não foi um empreendedor sozinho que começou não."

Respondente 3: "Não sei se foi uma pessoa que teve a idéia, mas já existia há muito tempo lá fora, mas não sei ao certo como aconteceu este processo, apenas que iniciou-se primeiramente em São Paulo."

A partir das respostas pode-se perceber que não existe um consenso sobre como começou a crescer a ideia de realizar os eventos, apenas que a ideia dos food trucks veio dos Estados Unidos (como explicado no capítulo 1) e que a ideia dos eventos começou em São Paulo. Mas as respostas parecem apontar para o indício de que os food trucks foram uma criação espontânea, nascida naturalmente a partir da observação de que o fenômeno estava dando certo em outros países, e que a partir daí foi "trazido" para o Brasil. Não há informação, no entanto, se a utilização dos eventos foi um fenômeno brasileiro, como forma de divulgar este tipo de empreendimento e aproveitar-se da facilidade de mobilidade dos food trucks para que pudessem ser realizados em vários locais diferentes, até que a atividade fosse formalmente regulada pelo governo.

A quarta e última pergunta foi relacionada às estratégias de divulgação dos eventos: "Você sabe quais são as estratégias utilizadas pelas empresas que organizam os eventos para torná-los conhecidos?".

Respondente 1: "Bom basicamente são as mesmas estratégias que as nossas individualmente, através de redes sociais, mas também depende de aonde o evento vai ser realizado. Por exemplo, existe um evento que acontece num condomínio da barra, então eles direcionam mais essa divulgação para os moradores do condomínio."

Respondente 2: "Bom acredito que mais redes sociais, jornais, busdor, mas aparentemente o melhor meio e o mais utilizado é através das redes sociais mesmo."

Respondente 3: "Redes sociais, revista de bairro, jornais, basicamente."

A partir das respostas colhidas, podemos perceber que existe uma tendência a utilizar-se essencialmente das redes sociais para promover os eventos, da mesma forma que acontece com os empreendedores individualmente. Tal efeito pode dar-se também devido ao direcionamento do público alvo dos eventos, possivelmente mais direcionado ao público jovem. 


\subsection{Descrição do perfil da amostra}

Para a amostra da pesquisa quantitativa, não foi utilizado um público alvo específico, uma vez que o objetivo da pesquisa era o de descobrir qual a eficácia das estratégias de divulgação tanto dos eventos quanto dos empreendedores individualmente, além de descobrir qual é o público alvo para este novo mercado. A seguir estão discriminadas as respostas colhidas referentes à descrição do perfil da amostra e ao público alvo deste tipo de empreendimento:

Tabela 1: Respostas da questão 8.

\begin{tabular}{|c|c|c|}
\hline \multicolumn{2}{|c|}{ 8. Qual o seu sexo? } \\
\hline Resposta & $\begin{array}{c}\text { Quantidade de } \\
\text { respostas }\end{array}$ & Percentual \\
\hline Masculino & 60 & $59 \%$ \\
\hline Feminino & 41 & $41 \%$ \\
\hline Total & 101 & $100 \%$ \\
\hline
\end{tabular}

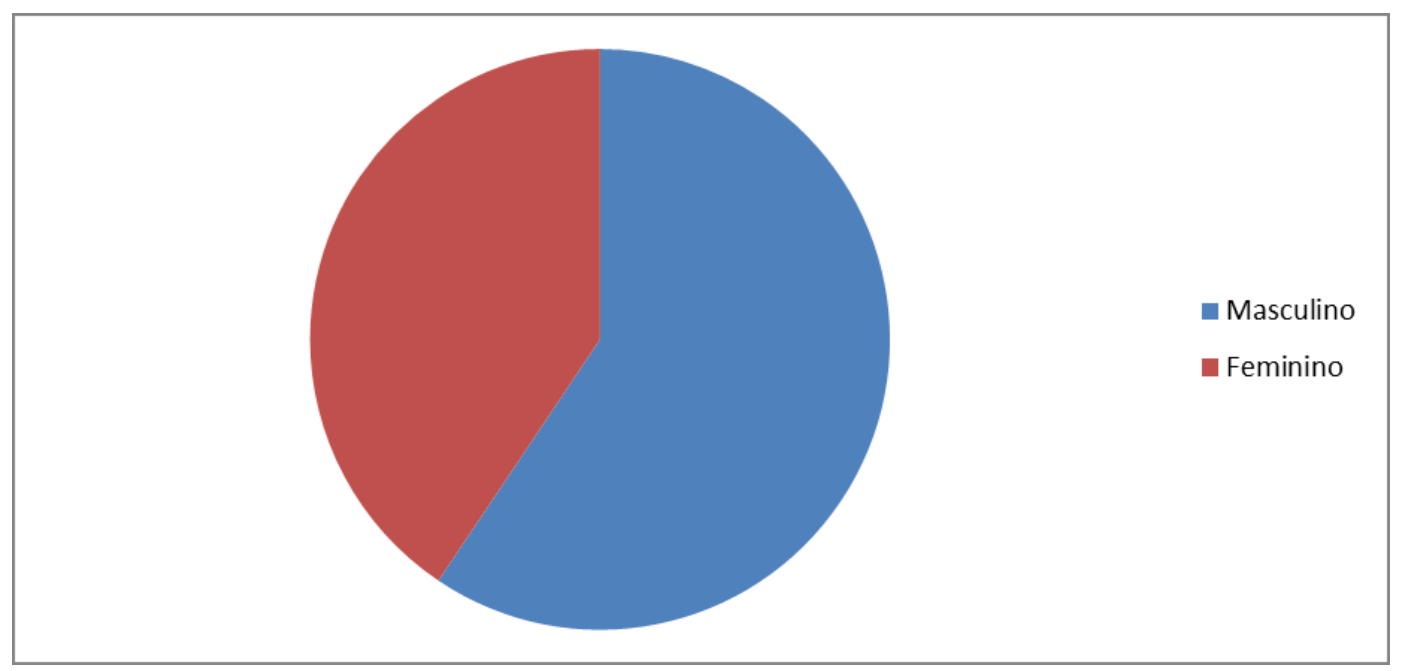

Gráfico 2: Gráfico da questão 8. Fonte primária

O percentual de respondentes do sexo masculino para este questionário foi de aproximadamente $60 \%$, enquanto que os de sexo feminino foram de aproximadamente $40 \%$. Cabe ressaltar que não houve distinção na distribuição dos questionários.

Tabela 2: Respostas da questão 9.

\begin{tabular}{|c|c|c|}
\hline \multicolumn{2}{|c|}{ 9. Qual a sua idade? } \\
\hline Resposta & $\begin{array}{c}\text { Quantidade de } \\
\text { respostas }\end{array}$ & Percentual \\
\hline Até 18 anos & 7 & $7 \%$ \\
\hline Entre 19 e 25 anos & 67 & $66 \%$ \\
\hline Entre 26 e 32 anos & 9 & $9 \%$ \\
\hline Entre 33 e 39 anos & 1 & $1 \%$ \\
\hline Acima de 39 anos & 17 & $17 \%$ \\
\hline Total & 101 & $100 \%$ \\
\hline
\end{tabular}




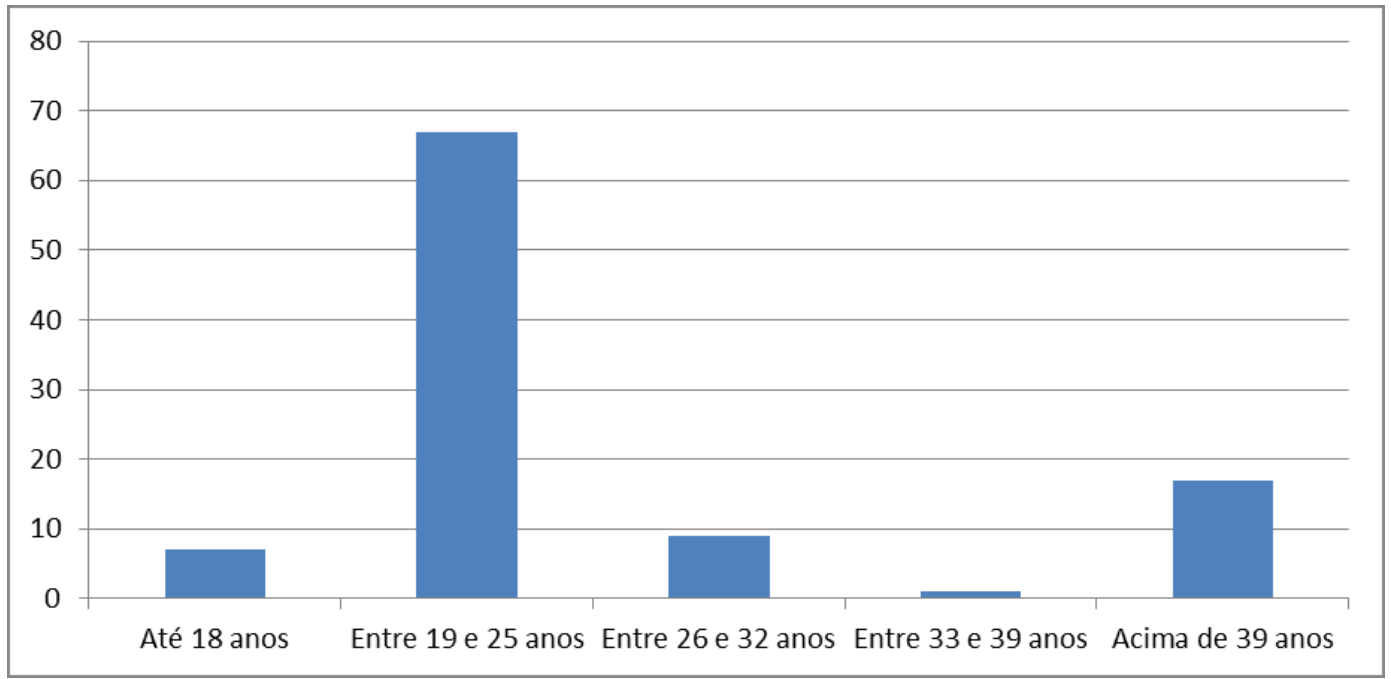

Gráfico 3: Gráfico da questão 9. Fonte primária

A faixa etária com maior representatividade para as respostas do questionário foi a de pessoas entre 19 e 25 anos, sendo responsável por 66\% das respostas. Parte da explicação para tamanha diferença no número de respostas pode ser o meio utilizado para distribuir as respostas (facebook), bem como o fato de ser justamente a faixa etária do círculo social das pessoas que distribuíram o questionário.

Tabela 3: Respostas da questão 10.

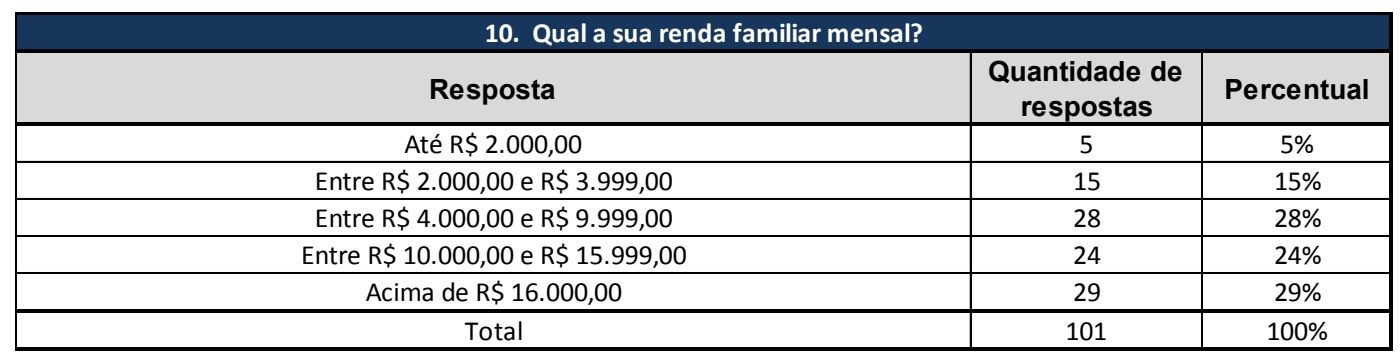

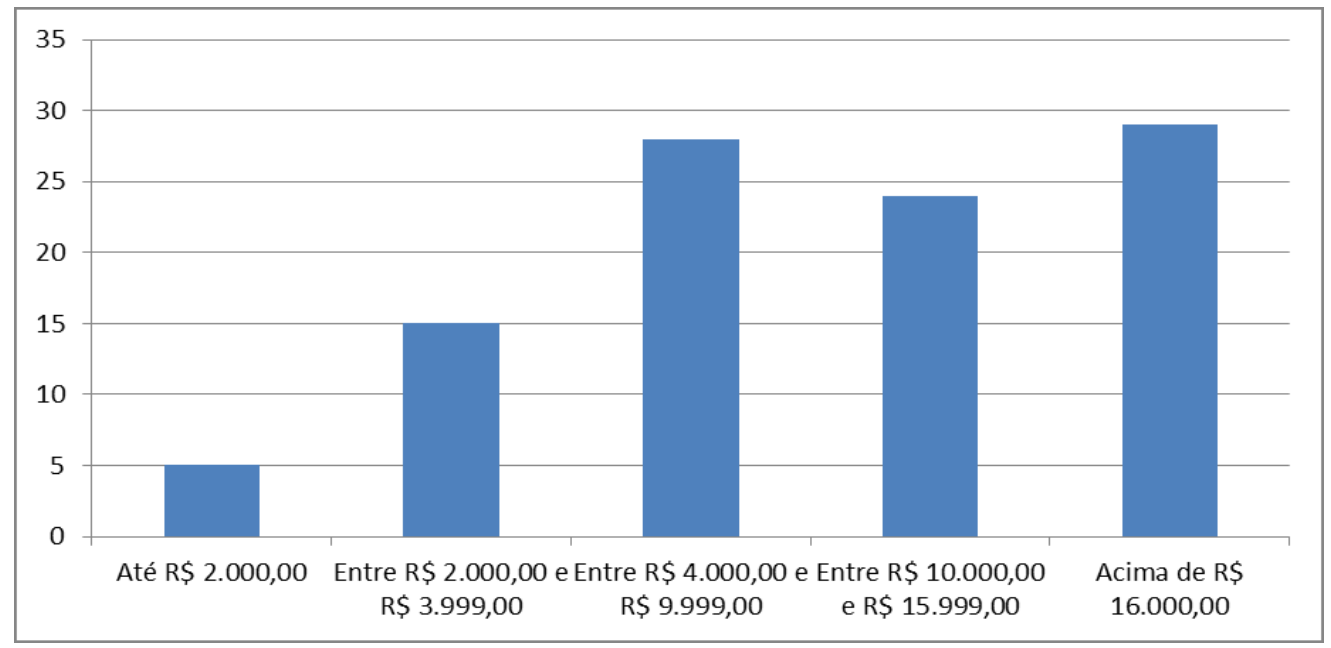

Gráfico 4: Gráfico da questão 10. Fonte primária 
A maior parte dos respondentes (mais de $80 \%$ ) possui renda familiar acima de $R \$ 4.000,00$ mensais, sendo $29 \%$ acima de $R \$ 16.000,00$ e $24 \%$ entre $R \$$ $10.000,00$ e $R \$ 15.599,00$. Considerando-se que a metodologia da FGV para definição de classe $A$ é a de pessoas que possuam renda familiar mensal acima de $\mathrm{R} \$ 9.745,00$, podemos dizer que a maior parte $53 \%$ pode ser classificado desta forma.

\subsection{Descrição e análise dos resultados do questionário}

As análises realizadas a seguir foram originadas a partir das respostas de um questionário enviado e respondido através da plataforma Qualtrics. O questionário é composto de 10 questões, e foram totalizadas 101 respostas. Como forma de aprofundar a análise e procurar sanar dúvidas que não poderiam ser respondidas pelas questões individualmente, foram feitos também cruzamentos entre as respostas de algumas delas, estando estes cruzamentos localizados após as perguntas utilizadas no cruzamento.

O objetivo central desta etapa da pesquisa foi o de analisar se as estratégias de divulgação (promoção) utilizadas tanto por donos de food truck quanto pelos planejadores dos eventos de food trucks estão conseguindo atrair o interesse da população carioca, além de identificar quais são as estratégias mais eficazes, e de quem é a responsabilidade por estas estratégias.

A seguir trataremos de cada questão e de cada cruzamento individualmente, com o objetivo de facilitar tanto a análise quanto a leitura e compreensão desta. As análises das três últimas questões (questionando gênero, faixa etária e renda familiar), por serem relacionadas ao perfil dos respondentes, estão localizadas na seção anterior (4.4).

Tabela 4: Respostas da questão 1.

\begin{tabular}{|c|c|c|}
\hline Resposta & $\begin{array}{l}\text { Quantidade de } \\
\text { respostas }\end{array}$ & Percentual \\
\hline Sim & 93 & $92 \%$ \\
\hline Não & 8 & $8 \%$ \\
\hline Total & 101 & $100 \%$ \\
\hline
\end{tabular}




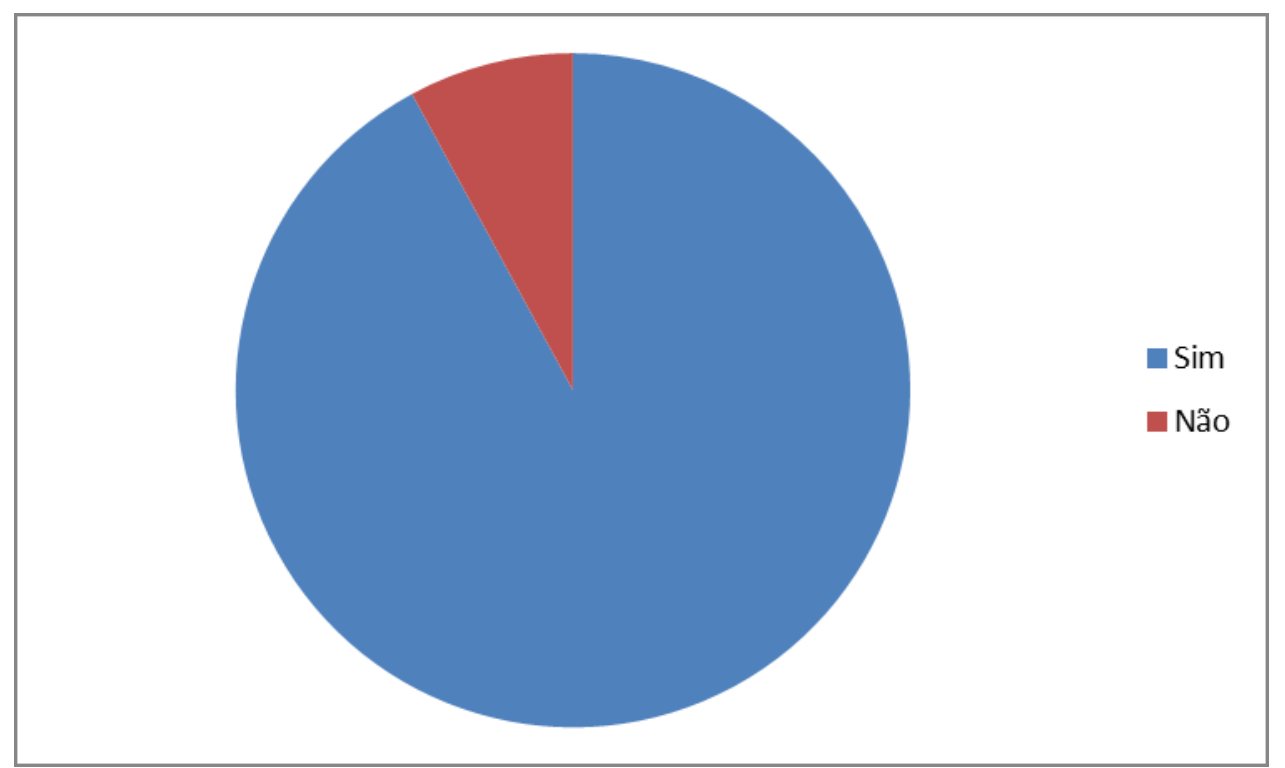

Gráfico 5: Gráfico da questão 1. Fonte primária

A primeira pergunta, "Você já ouviu falar em food truck?", possui o objetivo de identificar qual foi o percentual de pessoas que já ouviram falar no termo food truck, assim servindo para indicar o grau de notoriedade deste novo mercado entre a população carioca. Analisando as respostas à esta pergunta, percebemos o quão bom é o grau de efetividade dos meios de divulgação deste novo mercado: $92 \%$ dos pesquisados já ouviram falar, ou seja, apenas $8 \%$ nunca haviam ouvido falar sobre os food trucks. Tal percentual sugere que, pelo menos no que tange a fazer com que a mensagem chegue ao consumidor, as estratégias parecem estar surtindo efeito. Vale lembrar que os eventos e a "febre" dos food trucks começou em setembro de 2014, ou seja, em menos de um ano quase todos os respondentes da pesquisa haviam ouvido falar neles.

Tabela 5: Respostas da questão 2.

\begin{tabular}{|c|c|c|}
\hline \multicolumn{2}{|c|}{ 2. Você já ouviu falar nos eventos de food truck? } \\
\hline Resposta & $\begin{array}{c}\text { Quantidade de } \\
\text { respostas }\end{array}$ & Percentual \\
\hline Sim & 75 & $74 \%$ \\
\hline Não & 26 & $26 \%$ \\
\hline Total & 101 & $100 \%$ \\
\hline
\end{tabular}




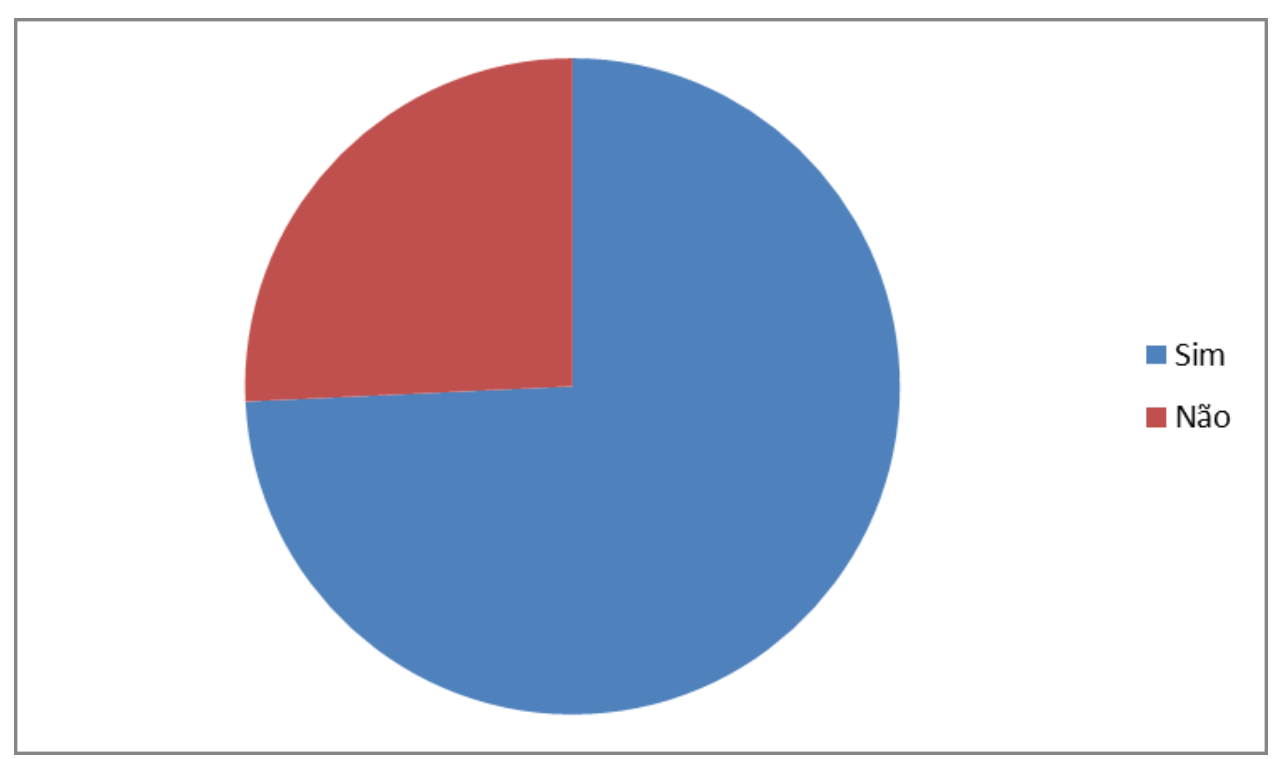

Gráfico 6: Gráfico da questão 2. Fonte primária

A segunda pergunta, "Você já ouviu falar nos eventos de food truck?" é uma variação da primeira pergunta, e possui o objetivo de analisar se os meios de divulgação dos eventos estão conseguindo alcançar a população carioca em geral. A partir dos resultados percebemos que aproximadamente três quartos (75\%) dos respondentes já havia ouvido falar nos food trucks, o que é um resultado que pode ser considerado bom, tendo em vista que existe menos de um ano desde que o primeiro evento no Rio de Janeiro ocorreu.

Tabela 6: Respostas do cruzamento entre as questões 1 e 2.

\begin{tabular}{|c|c|c|c|c|}
\hline & & \multicolumn{2}{|c|}{ Você já ouviu falar em food truck? } & \multirow[b]{2}{*}{ Total } \\
\hline & & Sim & Não & \\
\hline \multirow{3}{*}{ Você já ouviu falar nos eventos de food truck? } & Sim & 75 & 0 & 75 \\
\hline & Não & 18 & 8 & 26 \\
\hline & Total & 93 & 8 & 101 \\
\hline
\end{tabular}

O cruzamento entre as perguntas 1 e 2 ("Você já ouviu falar em food truck" e "Você já ouviu falar nos eventos de food truck") possui o objetivo de entender qual percentual de pessoas que já ouviram falar em food truck e que também ouviram falar nos eventos, desta forma buscando entender se as pessoas ficaram conhecendo os food trucks por causa dos eventos ou se as pessoas ficaram sabendo dos eventos por causa dos food trucks. De acordo com o cruzamento entre as respostas das duas perguntas, das pessoas que ouviram 
falar nos food trucks, $81 \%$ ouviram falar nos eventos, sugerindo que o fenômeno dos food trucks está mais conhecido do que os eventos relacionados a eles.

Tabela 7: Respostas da questão 3.

\begin{tabular}{|c|c|}
\hline 3. Como ficou sabendo dos food trucks? Mais de uma resposta é possível. \\
\hline Resposta & $\begin{array}{c}\text { Quantidade de } \\
\text { respostas }\end{array}$ \\
\hline Redes sociais (facebook, instagram, twitter) & 49 \\
\hline Boca a boca & 26 \\
\hline Artigos na internet ou em jornais & 19 \\
\hline Televisão & 16 \\
\hline Nunca ouvi falar & 16 \\
\hline Outros meios (favor especificar) & 7 \\
\hline Comendo em food trucks & 5 \\
\hline Outdoor / busdoor & 3 \\
\hline YouTube & 1 \\
\hline Total & 1 \\
\hline
\end{tabular}

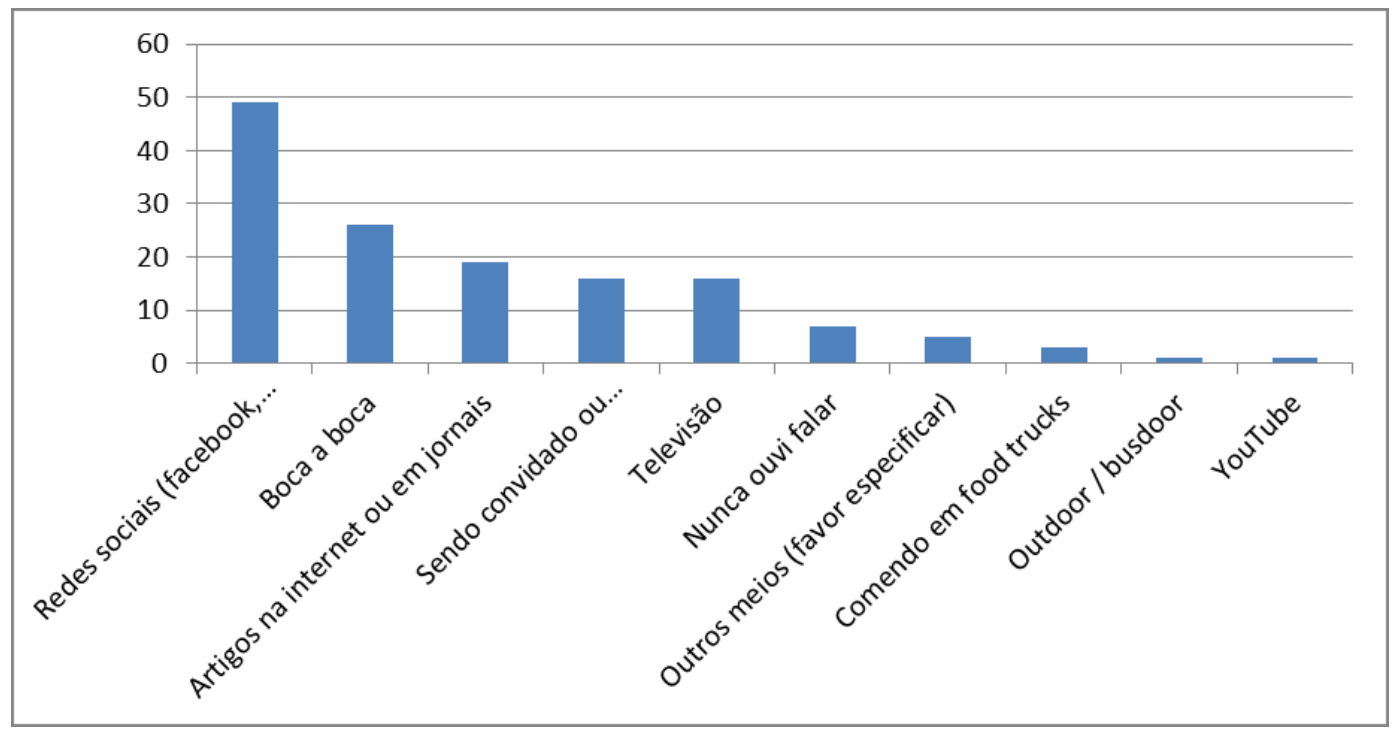

Gráfico 7: Gráfico da questão 3. Fonte primária

A terceira pergunta, "como você ficou sabendo dos food trucks?", visa entender qual meio de divulgação dos food trucks é o mais eficaz no que se refere a fazer com que a mensagem chegue aos potenciais consumidores. De acordo com as respostas, o meio mais eficaz são as redes socias, meio pelo qual $49 \%$ dos entrevistados ficaram sabendo dos food trucks. O segundo meio mais eficaz foi o boca a boca (26\%), seguido por artigos na internet ou em jornais $(19 \%)$ e sendo convidado ou participando de eventos de food trucks (16\%), com mesmo percentual de alcance ao público do que a televisão. Os outros meios de divulgação somados atingiram 10\% dos respondentes, enquanto que outros $7 \%$ não haviam ouvido falar nos food trucks. $O$ resultado 
obtido serve para demonstrar a força que os dois primeiros meios mais eficazes possuem: as redes sociais e o boca a boca. Embora o impacto das redes sociais fosse esperado, visto que a maior parte do esforço de marketing está direcionado para este meio, é surpreendente a disparidade entre esse meio e os outros. Os resultados também sugerem o poder do "boca a boca", demonstrando que tal fenômeno não pode ser ignorado pelos envolvidos. De acordo com o modelo de três estágios do consumidor de serviços, de Hoffman e Bateson (2001), o terceiro estágio, intitulado "avaliação pós-compra", é essencial para o reconhecimento e continuidade do negócio, uma vez que o feedback do cliente não só serve como forma de nortear os rumos do empreendimento, como também serve para "prever" se os comentários sobre a experiência de consumo do serviços serão positivas ou negativas, desta forma impactando no grau de confiança do consumior em determinada marca, e assim fazendo com que os próprios consumidores tenham participação na promoção desta. O resultado do meio de divulgação "boca a boca" aparenta estar indicando que as experiências de consumo de pessoas que consumiram em food trucks foram positivas, embora não exista meio de diferenciar se o impacto positivo do boca a boca está relacionado à experiência positiva dos clientes ou se trata-se meramente de empolgação com a novidade do fenômeno dos food trucks.

Tabela 8: Respostas da questão 4.

4. Caso já tenha experimentado a comida de food truck, aonde foi? Mais de uma resposta é possível.

\begin{tabular}{|c|c|}
\hline Resposta & $\begin{array}{c}\text { Quantidade de } \\
\text { respostas }\end{array}$ \\
\hline Não experimentei comida de food truck & 54 \\
\hline Na rua & 27 \\
\hline Eventos de food truck & 18 \\
\hline Eventos com presença de food trucks, porém não feitos exclusivamente para eles & 3 \\
\hline Total & 102 \\
\hline
\end{tabular}




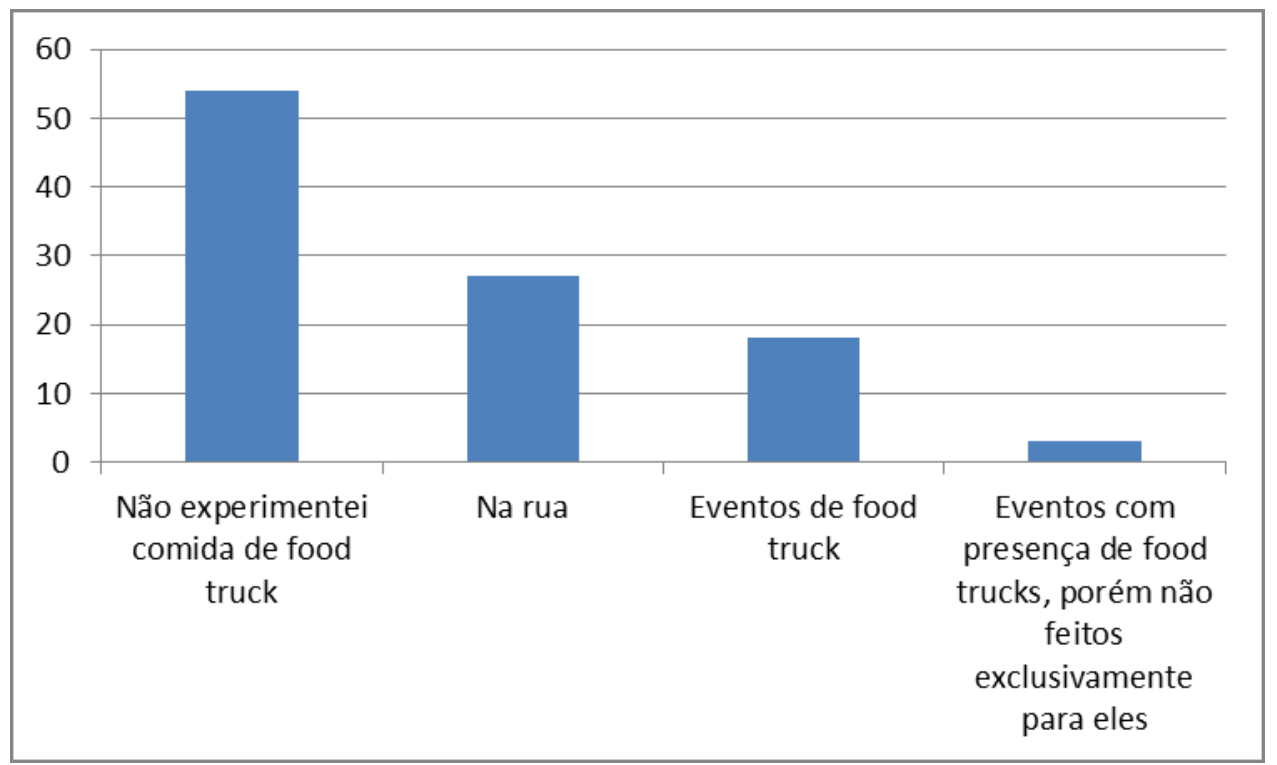

Gráfico 8: Gráfico da questão 4. Fonte primária

A quarta pergunta, "Caso já tenha experimentado a comida de food truck, aonde foi?", objetiva entender qual é o grau de responsabilidade dos eventos e dos food trucks individualmente no quesito de atrair efetivamente os consumidores aos locais de consumo. Esta pergunta se diferencia das duas primeiras, uma vez que as primeiras buscavam saber qual era o percentual de pessoas que haviam ouvido falar nos food trucks e nos eventos, podendo isto significar ou não que elas iriam participar/consumir em eventos e food trucks. Como forma de entender o grau de efetividade em atrair clientes para os food trucks, foram utilizadas as seguintes categorias de contatos com food trucks: eventos de food trucks; eventos com presença de food trucks, porém não feitos exclusivamente para eles; na rua; e por fim, pessoas que nunca experimentaram comida de food truck. De acordo com as respostas colhidas, a maior parte dos respondentes nunca experimentou comida de food trucks (53\%), enquanto que os que consumiram comida de food truck a consumiram predominantemente na rua $(27 \%)$ ou em eventos (18\%), ao passo que apenas $3 \%$ haviam consumido em eventos que continham food trucks, mas que não eram realizados apenas por causa destes. 
Tabela 9: Respostas do cruzamento entre as questões 3 e 4.

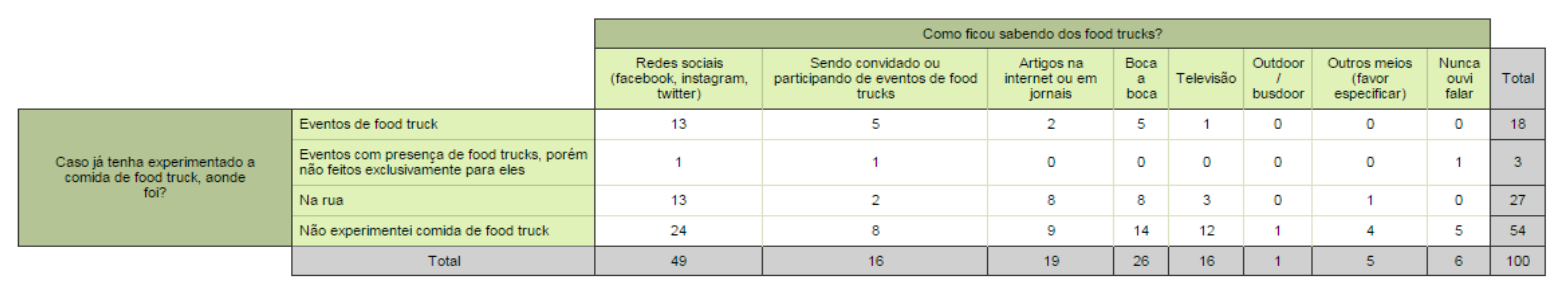

O cruzamento entre as perguntas "Como ficou sabendo dos food trucks?" e "Caso você já tenha experimentado comida de food truck, aonde foi?" busca entender qual dos meios de divulgação é responsável pelo melhor retorno em quantidade de clientes. Das pessoas que ficaram sabendo dos food trucks através de redes sociais, $27 \%$ foram a eventos de food truck, $27 \%$ comeram em food trucks na rua e $49 \%$ não experimentaram comida de food truck. Das pessoas que ficaram sabendo através de participação ou sendo chamados para eventos de food trucks, $33 \%$ participaram dos eventos, tendo os outros $67 \%$ sido chamados porém não foram. Das pessoas que ficaram sabendo através de boca a boca, $19 \%$ participaram dos eventos e $31 \%$ comeram em food trucks na rua, enquanto que os outros resultados de como as pessoas ficaram sabendo dos food trucks não foram expressivos. Comparando os diferentes meios, percebemos que os meios de divulgação que possuíram o maior retorno foram as redes sociais, aonde $54 \%$ das pessoas que entraram em contato com informação sobre food trucks tornaram-se clientes e o boca a boca, com $50 \%$ das pessoas que ouviram falar dos food trucks tendo participado dos eventos ou comido em food trucks na rua.

Tabela 10: Respostas da questão 5. 


\begin{tabular}{|c|c|c|}
\hline Resposta & $\begin{array}{c}\text { Quantidade de } \\
\text { respostas }\end{array}$ & Percentual \\
\hline 0 & 3 & $3 \%$ \\
\hline 1 & 1 & $1 \%$ \\
\hline 2 & 3 & $3 \%$ \\
\hline 3 & 10 & $10 \%$ \\
\hline 4 & 5 & $5 \%$ \\
\hline 5 & 13 & $13 \%$ \\
\hline 6 & 10 & $10 \%$ \\
\hline 7 & 19 & $19 \%$ \\
\hline 8 & 21 & $21 \%$ \\
\hline 9 & 8 & $8 \%$ \\
\hline 10 & 8 & $8 \%$ \\
\hline Total & 101 & $100 \%$ \\
\hline
\end{tabular}

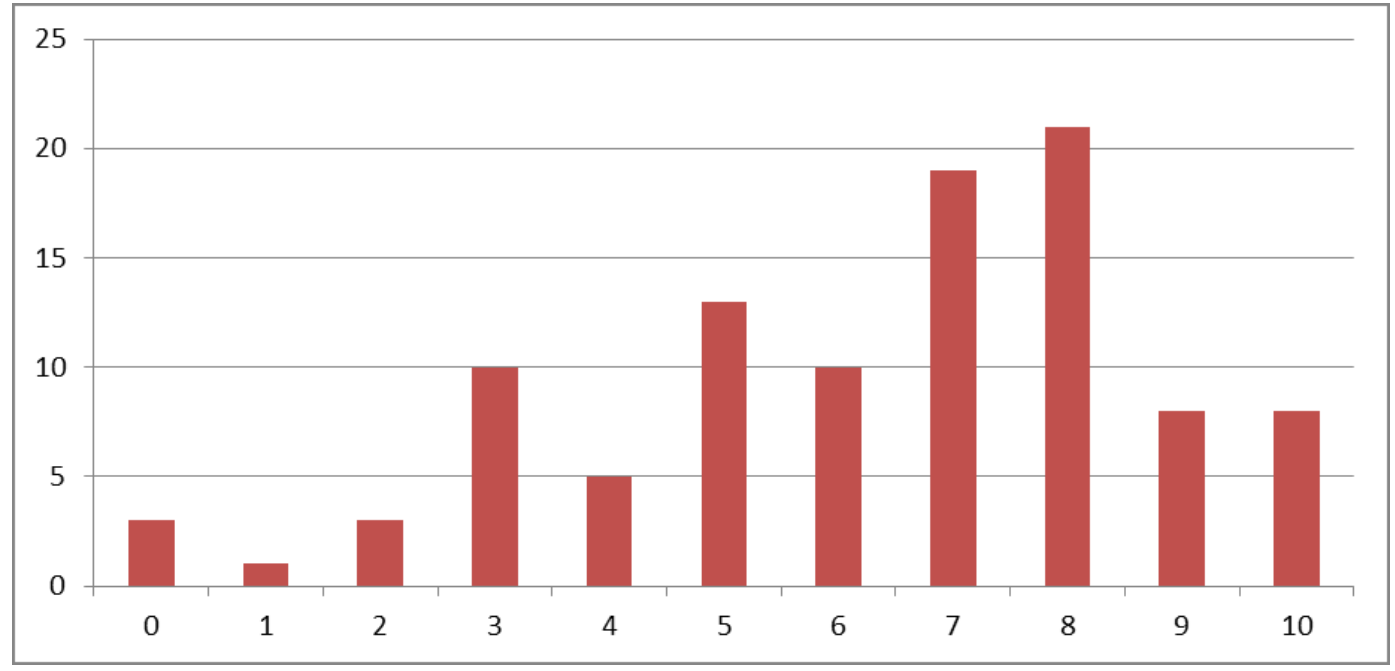

Gráfico 9: Gráfico da questão 5. Fonte primária

A quinta pergunta, "Em uma escala de 1 a 10, sendo 1 pouca vontade e 10 muita vontade, qual seria o seu grau de desejo de participar de um evento de food truck?", busca entender qual é a quantidade de pessoas que desejam participar dos eventos e qual é o grau de desejo delas de participar. Para facilitar a análise e a leitura, consideraremos que as notas abaixo de 5 indicam que a pessoa não possui interesse em participar do evento, notas entre 5 e 7 indicam um pouco de interesse e notas entre 8 e 10 indicam muito interesse. Sendo assim, temos que $22 \%$ dos respondentes não possuem interesse em participar dos eventos, $42 \%$ possuem pouco interesse de participar e $37 \%$ dos respondentes possuem muito interesse em participar. Esses dados nos servem para nos informar o grau de sucesso das estratégias de divulgação dos eventos, que aparentemente estão sendo bem-sucedidos, uma vez que $79 \%$ possui algum interesse em participar, sendo $37 \%$ com muito interesse. 
Tabela 11: Respostas da questão 6.

\begin{tabular}{|c|c|c|} 
6. Em uma escala de 1 a 10, sendo 1 pouca vontade e 10 muita vontade, qual seria o seu grau de desejo de comer em \\
um food truck na rua? & $\begin{array}{c}\text { Quantidade de } \\
\text { respostas }\end{array}$ & Percentual \\
\hline Resposta & 1 & $1 \%$ \\
\hline 0 & 0 & $0 \%$ \\
\hline 1 & 2 & $2 \%$ \\
\hline 2 & 2 & $2 \%$ \\
\hline 3 & 7 & $7 \%$ \\
\hline 4 & 13 & $13 \%$ \\
\hline 5 & 18 & $18 \%$ \\
\hline 6 & 19 & $19 \%$ \\
\hline 7 & 23 & $23 \%$ \\
\hline 8 & 7 & $7 \%$ \\
\hline 9 & 9 & $9 \%$ \\
\hline 10 & 101 & $100 \%$ \\
\hline Total & &
\end{tabular}

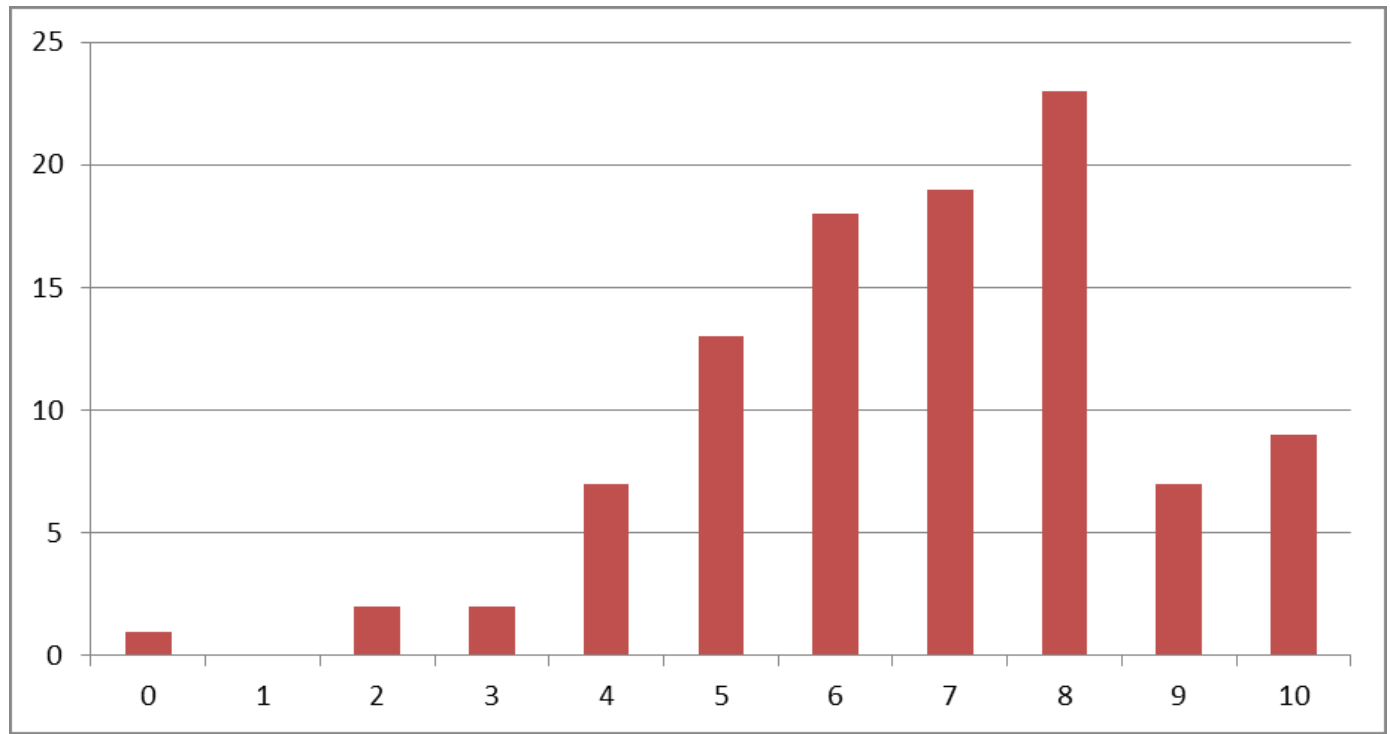

Gráfico 10: Gráfico da questão 6. Fonte primária

A sexta pergunta, "Em uma escala de 1 a 10, sendo 1 pouca vontade e 10 muita vontade, qual seria o seu grau de desejo de comer em um food truck na rua?" busca entender se existe alguma diferença na vontade de potenciais consumidores de consumir em food trucks em eventos ou na rua. Tal dúvida surge devido ao "preconceito" das classes altas contra comida de rua (devido à falta de higiene e de cuidados na hora do preparo), como explicitado por Pertile,Gastal e Guterres (2012). Embora o conceito de food truck seja destinado às classes mais altas e que os donos de food truck deixem claro para seus potenciais consumidores os cuidados com preparo, é possível que exista um certo temor em consumir produtos "da rua", o que pode acabar atrapalhando este segmento no futuro.

Para facilitar a análise e o entendimento desta, consideraremos que as notas abaixo de 5 indicam que a pessoa não possui interesse em participar do 
evento, notas entre 5 e 7 indicam um pouco de interesse e notas entre 8 e 10 indicam muito interesse. Sendo assim, temos que $12 \%$ dos respondentes não possuem interesse em comer em food trucks na rua, $50 \%$ possuem pouco interesse em comer em food trucks na rua e $39 \%$ dos respondentes possuem muito interesse em comer nos food trucks na rua. Como forma de entender se existe mesmo essa relutância em consumir comida de rua, é necessário comparar esses dados com os dados da questão anterior: na faixa de pessoas sem interesse em participar de eventos de food truck foram computadas $22 \%$ das respostas, ao passo que a mesma faixa (pessoas que não possuem vontade de frequentar food trucks na rua) desta questão foi computado $12 \%$ do total de respostas. Na faixa seguinte (pouca vontade de participar de eventos) foi a resposta de $42 \%$ na questão anterior, enquanto que esta faixa na questão atual obteve $50 \%$ das respostas. Na última faixa na questão anterior, tivemos que $37 \%$ dos respondentes teriam muita vontade em participar dos eventos, enquanto que na questão atual, o percentual de respondentes com muita vontade de comer em food trucks na rua foi de $39 \%$. Analisando essa comparação entre as questões, podemos deduzir que, embora o argumento de Pertile,Gastal e Guterres (2012) possa ter fundamento quando se avalia os tradicionais meios de comércio de comida de rua, os food trucks não são afetados por este "preconceito", visto que a comparação realizada entre as duas perguntas (vontade de participar de eventos de food truck e vontade de comer em food trucks nas ruas) nos permite afirmar que existe uma vontade maior de comer em food trucks nas ruas do que em eventos.

Tabela 12: Respostas da questão 7.

\begin{tabular}{|c|c|c|c|c|c|c|}
\hline Resposta & $\begin{array}{l}\text { Concordo } \\
\text { totalmente }\end{array}$ & $\begin{array}{c}\text { Concord } \\
0\end{array}$ & \begin{tabular}{|c|} 
Não \\
concord \\
o nem \\
discordo
\end{tabular} & Discordo & $\begin{array}{l}\text { Discordo } \\
\text { totalmente }\end{array}$ & $\begin{array}{c}\text { Quantidade } \\
\text { de } \\
\text { respostas }\end{array}$ \\
\hline O evento foi bem organizado. & 7 & 13 & 5 & 2 & 1 & 28 \\
\hline A comida era saborosa. & 7 & 16 & 2 & 2 & 1 & 28 \\
\hline A comida era sofisticada. & 7 & 13 & 7 & 0 & 1 & 28 \\
\hline A comida aparentava obedecer aos padrões de higiene e qualidade. & 10 & 14 & 2 & 0 & 2 & 28 \\
\hline O ambiente era animado. & 12 & 13 & 2 & 0 & 1 & 28 \\
\hline A localização era boa. & 6 & 13 & 5 & 4 & 0 & 28 \\
\hline Não houve dificuldades para estacionar no evento & 4 & 5 & 10 & 7 & 2 & 28 \\
\hline
\end{tabular}




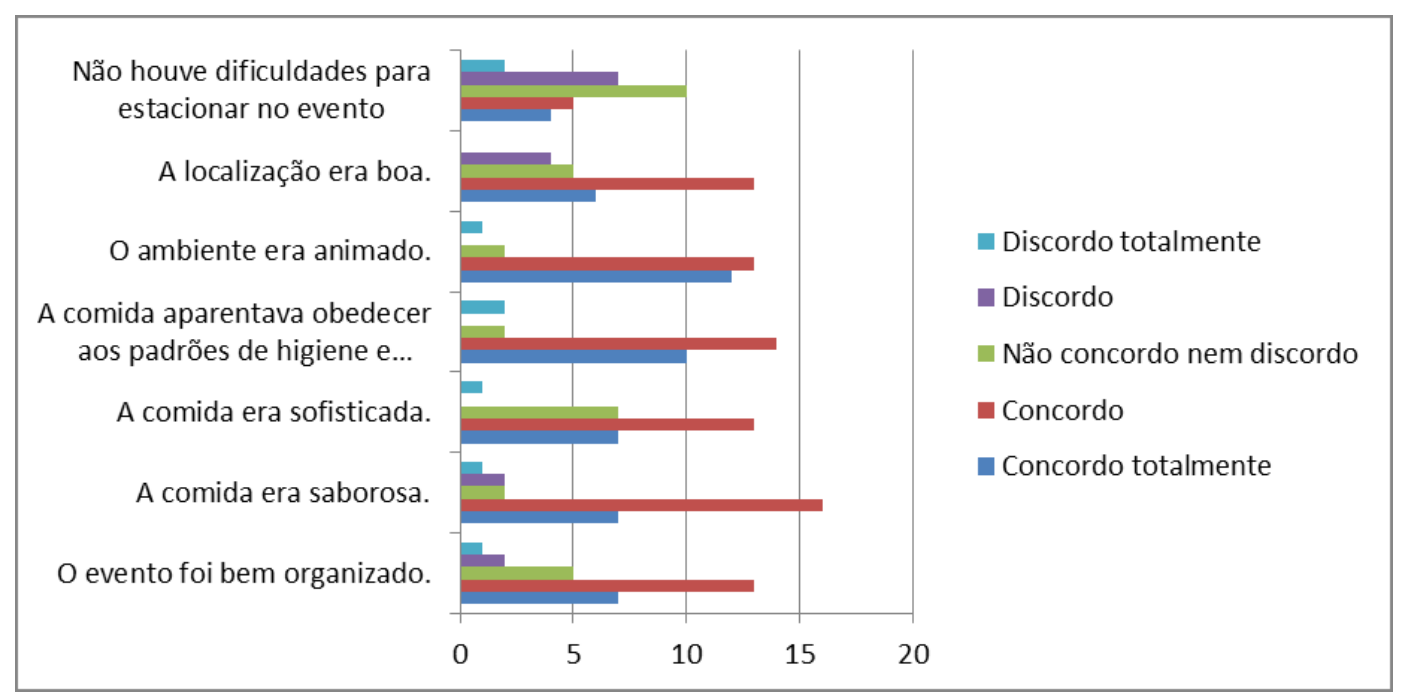

Gráfico 11: Gráfico da questão 7. Fonte primária

A sétima questão, que é condicionada a pessoas que participaram de eventos de food truck, consiste de sete afirmativas relacionadas à experiência dos respondentes nos eventos de food truck, e possui o objetivo de avaliar e servir de feedback aos organizadores destes eventos. Esta questão é fundamental para entender o pensamento dos frequentadores e, desta forma, adaptar-se a eventuais pontos negativos existentes na percepção dos clientes. De acordo com o modelo de três estágios de comportamento do consumidor de serviços de Hoffman e Bateson (2001), o estágio de consumo dos serviços diferencia-se bastante do consumo de bens, uma vez que o ato de compra, uso (consumo) e descarte destes últimos são realizados em ações diferentes, enquanto que quando se trata de serviços, esses três atos acontecem concomitantemente. Diferenciar todos os fatores que influenciam a opinião dos clientes sobre serviços requer, portanto, um esforço maior de diferenciação e análise destes três atos que acontecem durante o consumo de serviços.

A primeira afirmativa foi "O evento foi bem organizado.", com o objetivo de descobrir se a infraestrutura, filas e sistema de compra de tickets para venda dos itens estava contribuindo para uma boa imagem do negócio para os clientes ou atrapalhando. Os resultados foram: $25 \%$ dos clientes concordam totalmente com a afirmativa, 46\% concordam, 18\% não concordam nem discordam, 7\% discordam e $4 \%$ discordam totalmente. Pode-se dizer que, no geral, o evento possui uma boa infraestrutura e que possivelmente a eventual formação de filas não chegava a interferir na imagem dos eventos.

A segunda afirmativa foi "A comida era saborosa.", e seu objetivo era descobrir se o sabor da comida estava contribuindo para uma boa imagem do evento para seus clientes. As respostas foram: $25 \%$ concordam totalmente, $57 \%$ 
concordam, 7\% não concordam nem discordam, 7\% discordam e 4\% discordam totalmente. O grau de concordância com esta afirmativa aparenta possuir o mesmo padrão que o da questão sobre a organização do evento, o que pode ser considerado positivo para a imagem destes, uma vez que $83 \%$ dos respondentes concordam totalmente ou concordam com a afirmativa, desta forma demonstrando que, no geral, a comida possui um bom paladar, na visão de seus frequentadores.

A terceira afirmativa foi "A comida era sofisticada.", visando descobrir se a comida possuia o "apelo gourmet" que diferencia este segmento de mercado de outras comidas de rua. As respostas foram: $25 \%$ concordam totalmente, $46 \%$ concordam, 25\% não concordam nem discordam, $0 \%$ discordam e $4 \%$ discordam totalmente. Analisando os dados, percebemos que o retorno para esta questão foi positivo, porém com uma quantidade um pouco maior de neutralidade (não concordo nem discordo), demonstrando assim que o grau de concordância com a sofisticação da comida de food truck nos eventos é ligeiramente menor do que a concordância nas questões anteriores.

A quarta afirmativa, "A comida aparentava obedecer aos padrões de higiene e qualidade." visava descobrir se o fato de tratar-se de "comida de rua" alterava a percepção sobre higiene que esses empreendimentos passavam aos seus frequentadores. Da mesma forma que na questão 6 ("Em uma escala de 1 a 10 , sendo 1 pouca vontade e 10 muita vontade, qual seria o seu grau de desejo de participar de um evento de food truck?"), novamente procura-se identificar qualquer traço do "preconceito" das classes mais altas com "comida de rua" descritos por Pertile, Gastal e Guterres (2012). As respostas foram: 36\% concordam totalmente com a afirmação, $50 \%$ concordam, $7 \%$ não concordam nem discordam, $0 \%$ discordam e $7 \%$ discordam totalmente. Analisando os dados obtidos através destas respostas, podemos novamente (da mesma forma que na análise da questão 6) confirmar a hipótese de que este "preconceito" não atinge os food trucks, devido possivelmente aos esforços dos donos de food truck e envolvidos neste processo em passar ao cliente o máximo de transparência e confiabilidade quanto aos cuidados com procedência, armazenagem e preparo dos produtos e com a higiene nos processos.

A quinta afirmativa, "O ambiente era animado.", visava descobrir se a ambientação dos eventos contribuia positivamente para a imagem deles. As respostas foram: $43 \%$ concordaram totalmente, $46 \%$ concordaram, $18 \%$ não concordaram nem discordaram, $14 \%$ discordaram e $0 \%$ discordaram totalmente. As respostas demonstram que aparentemente 0 ambiente contribui 
positivamente para a imagem dos eventos, evidenciado pelo fato de que $89 \%$ concordam totalmente ou concordam que o ambiente era animado.

A sexta afirmativa foi "A localização era boa.", cujo objetivo era descobrir se a localização dos eventos estava causando uma boa imagem para os clientes. As respostas foram: $21 \%$ concordam totalmente, $46 \%$ concordam, $18 \%$ não concordam nem discordam, $14 \%$ discordam e $0 \%$ discordam totalmente. 0 grau de concordância com esta questão indica uma ligeira maior insatisfação que nas questões anteriores, uma vez que, apesar de $67 \%$ concordarem em algum grau com a afirmativa, o grau de concordância é maior do que de concordância total. Além disso, existe um grau considerável de neutralidade (18\%) e de discordância (14\%), apesar de não haver discordância total. Estas respostas aparentam indicar que a localização dos eventos contribui em menor grau para a imagem dos eventos do que as outras afirmativas.

A sètima afirmativa, "Não houve dificuldades para estacionar no evento." visava descobrir se a limitação espacial dos estacionamentos e da oferta de vagas comparada à quantidade de visitantes dos eventos estava contribuindo para uma má imagem deste quesito para os eventos. As respostas foram: 14\% concordaram totalmente com a afirmativa, 18\% concordaram, 36\% não concordaram nem discordaram, 25\% discordaram e 7\% discordaram totalmente. Analisando estas respostas e comparando-as com as outras, pode-se perceber que esta possui um grau de concorância e de concordância total muito menor do que nas outras afirmativas (32\%). Além disso, existe um grande núnero de respondentes neutros ( $36 \%$ não concordam nem discordam) e 32\% discordam, sendo $7 \%$ o percentual de respondentes que discordam totalmente com a afirmativa. Estes números apontam para que o fator "dificuldade para estacionar/achar vagas" contribua negativamente para a imagem dos eventos, e pode, caso não seja solucionado no futuro, prejudicar a imagem destes a longo prazo.

Tabela 13: Respostas do cruzamento entre as questões 4 e 8.

\begin{tabular}{|c|c|c|c|c|c|c|}
\hline & & \multicolumn{4}{|c|}{ Caso já tenha experimentado a comida de food truck, aonde foi? } & \\
\hline & & Eventos de food truck & Eventos com presença de food trucks, porém näo feitos exclusivamente para eles & Na rua & Não experimentei comida de food truck & Total \\
\hline \multirow{3}{*}{ Qual o seu sexo? $\square$} & Masculino & 8 & 2 & 20 & 30 & 60 \\
\hline & Feminino & 10 & 1 & 7 & 24 & 40 \\
\hline & Total & 18 & 3 & 27 & 54 & 100 \\
\hline
\end{tabular}


O cruzamento entre as perguntas "Caso você já tenha experimentado a comida de food truck, aonde foi?" e "Qual é o seu sexo?" visa entender se existe alguma correlação entre gênero e a predisposição em comer comida de food trucks ou frequentar os eventos. De acordo com os resultados, quase não há distinção de gênero quanto a ter participado de eventos de food trucks ou eventos com presença de food trucks ( $48 \%$ de homens participaram de eventos de/com food trucks contra $52 \%$ de mulheres). Existe, no entanto, uma disparidade muito grande quando se correlaciona gênero com ter experimentado comida de food trucks na rua: $74 \%$ dos que experimentaram food trucks de rua foram homens, enquanto que mulheres foram apenas $26 \%$. Apesar de não haver referência quanto às diferenças entre os gêneros na relação das pessoas com "comida de rua" no estudo de Pertile, Gastal e Guterres (2012), pode supor-se que haja relação entre gênero e "preconceito" com a comida de rua; porém para tanto seria necessário um estudo mais aprofundado, como forma de explicar a disparidade percebida nesta questão.

Tabela 14: Respostas do cruzamento entre as questões 4 e 9.

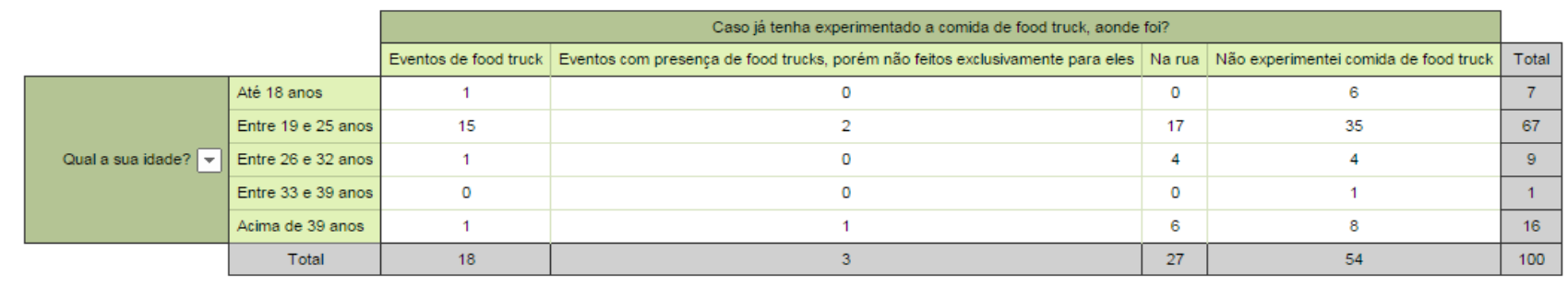

O cruzamento entre as perguntas "Caso você já tenha experimentado a comida de food truck, aonde foi?" e "Qual a sua idade?" visa entender se existe alguma correlação entre faixa etária e a disposição em comer ou frequentar eventos de food trucks. Analisando por faixa etária, vemos que dos 7 respondentes menores de 19 anos, apenas 1 participou de eventos de food truck ou eventos com food trucks, enquanto nenhum havia comida em food trucks na rua. $\mathrm{Na}$ faixa etária seguinte, de 19 a 25 anos, podemos ver que $25 \%$ dos respondentes participaram de eventos de food truck ou eventos com presença de food truck, enquanto que $25 \%$ havia experimentado comida de food truck na rua, sendo que $52 \%$ nunca havia participado dos eventos nem comido comida de food truck. Na faixa etária de 26 a 32 anos, apenas 1 respondente participou de eventos de food truck (11\%) e 4 respondentes experimentaram comida de food truck nas ruas ( $44 \%$ ), enquanto que $44 \%$ nunca haviam comido comida de food truck nem participado de eventos. Apenas um respondente encontrava-se 
na faixa de 33 a 39 anos, logo o resultado não é expressivo o suficiente para ser analisado (nunca comeu comida de food trucks). Na última faixa etária, acima de 39 anos, apenas 2 respondentes participaram de eventos de food trucks ou eventos com presença de food trucks (13\%), 6 respondentes haviam experimentado comida de food trucks na rua (38\%), enquanto que 8 respondentes (50\%) nunca experimentaram comida de food truck. Analisando os dados, podemos perceber que existe uma maior propenção para jovens de 19 a 25 anos participarem dos eventos de food trucks do que qualquer outra faixa etária, uma vez que um quarto deles participou. Comparando a partticipação nos eventos na faixa de 19 a 25 anos com as outras faixas etárias, podemos perceber que nenhuma chegou perto deste percentual (a segunda maior foi de $14 \%$, porém a amostra pequena dessa faixa etária inviabiliza uma análise mais profunda). Podemos perceber também que a única faixa etária que frequenta eventos de food truck na mesma proporção do que come em food trucks nas ruas é a de 19 a 25 anos (25\% particiou de eventos e $25 \%$ comeu em food trucks nas ruas), enquanto que nas outras faixas etárias a maioria dos respondentes comeu mais em food trucks nas ruas do que em eventos.

Tabela 15: Respostas do cruzamento entre as questões 4 e 10.

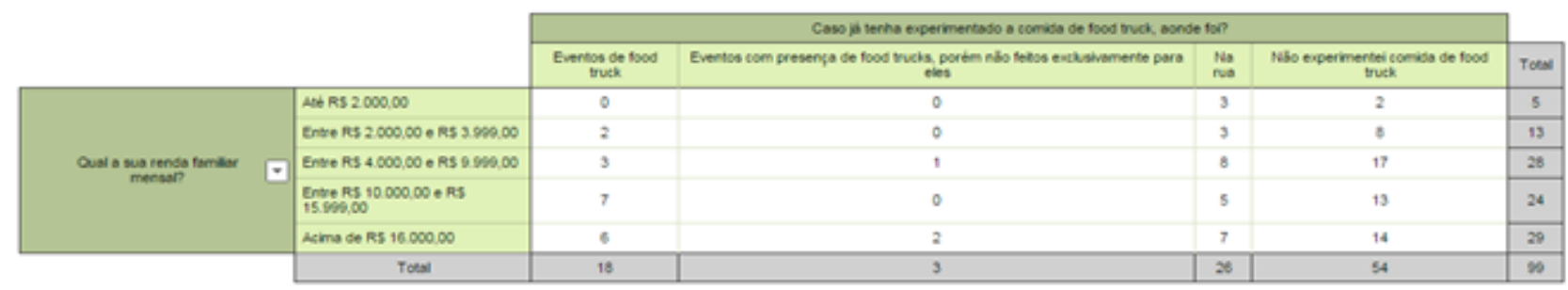

$\mathrm{Na}$ última correlação, foram cruzadas as perguntas "Caso já tenha experimentado comida de food truck, aonde foi?" com "Qual a sua renda familiar mensal?", como forma de descobrir se existe alguma relação entre renda e predisposição em comer em food trucks nas ruas ou em eventos. Na faixa de renda até $R \$ 2.000,00,3$ respondentes haviam comida em food trucks nas ruas, e 2 nunca haviam experimentado. Na faixa seguinte, entre $R \$ 2.000,00$ e $R \$$ $3.999,00,15 \%$ dos respondentes haviam participado de eventos, enquanto que $23 \%$ haviam experimentado comida de food trucks nas ruas. Na faixa entre $R \$$ $4.000,00$ e $\mathrm{R} \$ 9.999,00,14 \%$ dos respondentes participaram de eventos com food trucks e $29 \%$ comeram em food truccks na rua, enquanto que $61 \%$ não haviam comido em food trucks. Na faixa de renda familiar entre $R \$ 10.000,00$ e $15.999,00,29 \%$ dos respondentes participaram de eventos de food trucks ou 
com presença de food trucks, enquanto que $21 \%$ experimentaram comida de food trucks nas ruas e $58 \%$ nunca haviam experimentado comida de food trucks. $\mathrm{Na}$ última faixa de renda, acima de $\mathrm{R} \$ 16.000,00,28 \%$ dos respondentes afirmaram que foram a eventos de food trucks ou eventos com food trucks, enquanto que $24 \%$ dos respondentes frequentaram food trucks nas ruas e $48 \%$ nunca experimentaram comida de food truck. Analisando os dados obtidos, pode-se perceber uma pequena relação entre faixa de renda familiar e a participação em eventos de food trucks ou comer em food trucks nas ruas: as faixas de renda mais altas preferem frequentar eventos de food truck, ao passo que faixas de renda mais baixas frequentam mais food trucks nas ruas do que em eventos. 


\section{Conclusões e recomendações para novos estudos}

Este trabalho teve por objetivo investigar o fenômeno dos food trucks no Rio de Janeiro, sendo o seu conceito semelhante ao da comida de rua, porém com o diferencial de ser voltado para públicos de renda elevada. O crescimento deste novo segmento de mercado começou em setembro de 2014, impulsionado por eventos que reuniam diversos food trucks e que acabaram por dar mais notoriedade a este novo empreendimento, ao mesmo tempo em que se esperava a criação de legislação que permitisse e regulasse a utilização de food trucks em espaços públicos. Como forma de avaliar como a população carioca está reagindo ao processo de introdução deste novo segmento de mercado no Rio de Janeiro, este estudo procurou entender quais são as estratégias de divulgação deste novo segmento utilizadas pelos organizadores de eventos e empreeendedores, e descobrir se estas estratégias estão causando o efeito desejado na população.

Como forma de embasar a análise deste estudo foi utilizado referencial teórico de diversos autores e estudiosos das áreas de empreendedorismo, comportamento do consumidor e de marketing. Na área de empreendedorismo, buscou-se conhecimento sobre estratégias de criação de mercados não existentes - chamados pelos autores Kim e Mauborgne (2005) de estratégia do oceano azul - como forma de entender como se dá a criação de novos modelos de empreendimentos e o impacto destes nos potenciais consumidores. $\mathrm{Na}$ área de comportamento do consumidor, buscou-se entender como pensa o consumidor de comida de rua, tendo sido utilizados tanto artigos acadêmicos como publicações dos autores Maciel (2005), Pertile, Gastal e Guterres (2012), Tinker (1999) e Cardoso, Santos e Silva (2007); utilizados como base para o entendimento dos potenciais consumidores de food trucks. Como referencial de marketing, foram utilizados livros sobre marketing de serviços de Hoffman e Bateson (2001), bem como de Lovelock e Wright (2002), buscando compreender melhor as nuances do marketing de serviços, assim podendo analisar corretamente as estratégias utilizadas pelos empreendedores e organizadores de eventos. 
Para atingir os objetivos do trabalho, foram inicialmente propostas três etapas diferentes de pesquisas: a primeira, uma entrevista com o gestor marketing de uma empresas de eventos de food trucks, buscando compreender como foi o processo de introdução deste segmento de mercado no Rio de Janeiro e descobrir quais são as estratégias dos realizadores de eventos para torná-los mais conhecidos; a segunda etapa, composta de entrevistas com três donos de food trucks, procurou compreender quais são as estratégias utilizadas por eles para divulgar seus empreendimentos; na última etapa foi utilizado um questionário estruturado, cujo objetivo foi avaliar a eficácia das estratégias de divulgação dos eventos e dos food trucks individualmente, sendo definida como eficácia neste caso a capacidade de atração de clientes para eventos de food trucks e para food trucks nas ruas.

A etapa de entrevista com o gestor de empresa de eventos, no entanto, não pôde ser realizada, uma vez que foi tentado contato com mais de uma empresa, porém nenhuma retornou. Como forma de contornar isso, na etapa de entrevista com os donos de food truck foram realizadas as perguntas que seriam direcionadas aos gestores. O trabalho foi composto, afinal, por duas etapas: entrevistas com três donos de food trucks e questionário estruturado.

O questionário visou uma amostragem maior do que 100 respondentes, tendo as análises das respostas feitas através de cruzamentos entre as questões e a análise delas individualmente. Pelo fato de o objetivo do questionário ser descobrir a efetividade das campanhas de promoção (divulgação) dos food trucks, os questionários não foram destinados a um público-alvo específico.

Os dados das entrevistas foram tratados por análise de conteúdo, tendo as entrevistas sido realizadas por meio de um roteiro estruturado, gravadas e por fim transcritas.

De acordo com cruzamentos realizados entre perguntas sobre gênero, sexo e renda familiar com outras questões, foi descoberto quem deve ser o consumidor-alvo dos food trucks, podendo estes dados serem utilizados pelos donos e organizadores de eventos. Para empreendedores individuais que atuem nas ruas, o público alvo seriam homens, na faixa de 19 a 25 anos e com renda familiar mensal acima de $\mathrm{R} \$ 4.000,00$. Já para os eventos de food trucks, o público alvo seriam pessoas de qualquer gênero, na faixa etária entre 19 e 25 anos e com renda familiar mensal acima de $\mathrm{R} \$ 10.000,00$.

Uma dúvida que existia antes que o questionário fosse respondido era se poderia existir um certo preconceito com a comida dos food trucks, pelo fato de 
tratar-se de comida de rua, desta forma podendo ser associada à falta de higiene e às classes mais baixas, como explicitado por Pertile, Gastal e Guterres (2012). Após a análise das respostas do levantamento, no entanto, ficou claro que não existia este preconceito relacionado às comidas de food truck, com apenas um dado indicando uma certa associação entre renda familiar e propensão em participar de eventos ou comer em food trucks nas ruas (pessoas com renda familiar mais alta comem mais em food trucks nos eventos e pessoas com renda familiar mais baixa consomem em food trucks nas ruas), porém não é possível identificar, através desta questão, se isso se deve ao "preconceito" com comida de rua ou a outros fatores. Em outras questões as pessoas que participaram dos eventos foram perguntadas sobre a higiene dos processos e dos alimentados, tendo sido respondido pela maior parte que a comida aparentava obedecer aos padrões de higiene e qualidade. Em outra questão, foi perguntado a todos os respondentes sobre sua vontade de comer tanto em eventos de food trucks quanto em food trucks nas ruas. Comparando as respostas de ambas de ambos (eventos $\mathrm{x}$ food trucks nas ruas), as pessoas possuíam mais vontade de experimentar a comida de food trucks nas ruas do que em eventos, mesmo a quantidade de respondentes situados numa alta faixa de renda alta ter sido maior do que de baixa renda familiar.

Os resultados das pesquisas permitiram também avaliar o grau de efetividade das companhas de divulgação dos eventos de food trucks e dos food trucks individualmente nas redes sociais. Apesar de não ser surpreendente que as redes sociais são um dos meios mais eficazes de comunicação hoje em dia (especialmente para o público jovem, público alvo dos food trucks), pode-se observar que, dentre todos os meios de divulgação utilizados pelos eventos e pelos donos de food truck, as redes sociais foram o que trouxe proporcionalmente o maior de pessoas para os eventos e para os food trucks nas ruas (seguido pelo boca a boca, segundo meio mais eficaz)

Através do questionário se pôde também analisar quais são os fatores que influenciam a imagem dos eventos de food trucks para seus clientes. Foram feitas afirmações apenas para respondentes que participaram de eventos de food trucks sobre sete fatores que poderiam afetar a percepção dos frequentadores durante o consumo neles: organização do evento, sabor da comida, sofisticação da comida, higiene da comida, animação do ambiente, localização do evento e, por fim, dificuldade para estacionar no evento. De acordo com a análise da concordância dos respondentes com as afirmativas (com as concordâncias representando bons resultados para a imagem do 
evento), pôde-se perceber que o único fator que recebeu resultados ruins foi o que tratava da dificuldade de estacionar no local, o qual obteve a mesma quantidade de discordâncias do que concordâncias, enquanto que a quantidade de respostas neutras também foi a maior entre os fatores, a menor quantidade de concordâncias e a maior quantidade de discordâncias entre os fatores.

Por fim, foi possível perceber através deste estudo que os food trucks estão realmente conseguindo atingir seus objetivos, ou seja, não só fazer com que a novidade se espalhe (principalmente para seu público alvo) como também atrair pessoas tanto para os eventos quanto para os food trucks já em atividade. Os meios de divulgação dos eventos e dos food trucks individualmente também estão conseguindo atingir de forma eficaz potenciais clientes, ao mesmo tempo que a inovação acaba por atrair a atenção da mídia, o que facilita ainda mais os esforços de marketing dos envolvidos na inserção deste novo mercado no Rio de Janeiro.

\subsection{Sugestões e recomendações para novos estudos}

Este trabalho poderá servir como base para novos estudos sobre os food trucks, podendo estes estudos ser realizados por empresas envolvidas na introdução desse segmento de mercado (consultorias, empresas de publicidade, empresas de organização de eventos) como também podem ser feitos por associações de food trucks, como forma de melhorar as estratégias com o público-alvo, visando aumentar ainda mais a eficácia na divulgação tanto dos empreendedores individualmente como dos eventos.

Outro uso deste trabalho seria o de ser utilizado como base para um estudo mais aprofundado sobre a opinião dos frequentadores de eventos sobre estes, uma vez que os dados analisados podem ser utilizados como feedback para os donos de food trucks, podendo melhorar ainda mais as realizações destes eventos e a opinião dos clientes destes.

Um terceiro uso deste estudo seria aprofundar ainda mais a relação entre o "preconceito" com a comida de rua abordado na revisão de literatura e durante a condução deste trabalho e a visão do público-alvo (classes mais altas). 0 estudo poderia informar com mais precisão se existem, de fato, vestígios deste "preconceito" com comida de rua por parte de parcela das faixas de renda mais altas. Apesar de este estudo indicar que estes vestígios não existem na relação do público-alvo com os food trucks (ou que as estratégias de marketing conseguiram reduzir as dúvidas deste público com relação à higiene no preparo 
da comida), uma análise mais aprofundada (com maior tratamento estatístico e maior amostra) seria necessária para abordar esta questão com maior aprofundamento. 


\section{Referências Bibliográficas}

BATESON, J.E.G.; HOFFMAN, K.D. Marketing de Serviços. Porto Alegre: Bookman, 2001.

CARDOSO, R.C.V.; SANTOS, S.M.C.; SILVA, E.O. Comida de rua e intervenção: estratégias e propostas para o mundo em desenvolvimento. Ciência \& Saúde Coletiva, p. 1215-1224, 2009

CHAER, B. Food trucks e feiras mudam tradição que existe em SP há quase 200 anos. Folha de S. Paulo, São Paulo, 08 nov. 2014. Disponível em: < http://www1.folha.uol.com.br/saopaulo/2014/11/1544795-food-trucks-e-feirasmudam-tradicao-que-existe-em-sp-ha-quase-200-anos.shtml>. Acesso em: 15 de março de 2015.

KIM, W.C.; MAUBORGNE, R. A estratégia do Oceano Azul: Como criar novos mercados e tornar a concorrência irrelevante. São Paulo: Elsevier, 2005.

KOTLER, P. Administração de Marketing: Análise, Planejamento, Implementação e Controle. São Paulo: Atlas, 1996.

LOVELOCK, C.; WRIGHT, L. Serviços, Marketing e Gestão. São Paulo: Saraiva, 2002.

MACIEL, M.E. Olhares antropológicos sobre a alimentação: Identidade cultural e alimentação. Antropologia e nutrição: um diálogo possível, p. 49-55, 2005

PERTILE, K.; GASTAL, S.; GUTERRES, L.S. Comida de rua: Relações históricas e conceituais. IX Seminário da Associação Nacional Pesquisa e Pós-Graduação em Turismo. São Paulo: Anptur - Universidade Anhembi Morumbi, 2012.

SPINACÉ, N. A invasão dos food trucks. Revista Época, Rio de Janeiro, 24 set. 2014. Disponível em: < http://epoca.globo.com/vida/vida-util/gastronomia-eestilo/noticia/2014/09/invasao-dos-bfood-trucksb.html>. Acesso em 17 de março de 2015.

TINKER, I. Street foods into the 21st century. Agriculture and Human Values, p. 327-333, 1999 


\section{Anexo 1}

\section{Questionário - Food trucks}

As perguntas a seguir referem-se aos food trucks e aos eventos relacionados a estes. Para este questionário seräo considerados como food trucks especificamente os novos tipos de empreendimentos, uma vez que 0 termo food truck poderia abranger empreendimentos similares, porém mais tradicionals (como carrinhos de cachorro quente).

Agradeço desde já pela cooperaçäol

Você já ouviu falar em food truck?

Sim

Não

Você já ouviu falar nos eventos de food truck?

Sim

Não

Como ficou sabendo dos food trucks? Mais de uma resposta é possível.

Redes sociais (facebook, instagram, twitter)

Sendo convidado ou participando de eventos de food trucks

Artigos na internet ou em jornais

Boca a boca

Televisäo

Outdoor / busdoor

Outros meios (favor especificar)

Nunca ouvi falar 
Caso já tenha experimentado a comida de food truck, aonde foi? Mais de uma resposta é possivel.

Eventos de food truck

Eventos com presença de food trucks, porém não feitos exclusivamente para eles Na rua

Näo experimentei comida de food truck

Em urna escala de 1 a 10, sendo 1 pouca vontade e 10 muita vontade, qual seria o seu grau de desejo de participar de um evento de food truck?
0
2
34
56
$\begin{array}{lll}7 & 8 & 9\end{array}$
10

Em uma escala de 1 a 10 , sendo 1 pouca vontade e 10 muita vontade, qual seria o seu grau de desejo de comer em um food truck na rua?

$\begin{array}{lllllllllll}0 & 1 & 2 & 3 & 4 & 5 & 6 & 7 & 8 & 9 & 10\end{array}$

Caso tenha participado de um evento de food truck, favor marcar nas opções o grau de concordância com as afirmativas:

\begin{tabular}{|c|c|c|c|c|c|}
\hline & $\begin{array}{l}\text { Concordo } \\
\text { totalmente }\end{array}$ & Concordo & $\begin{array}{l}\text { Näo } \\
\text { concordo } \\
\text { nern } \\
\text { discordo }\end{array}$ & Discordo & $\begin{array}{l}\text { Discordo } \\
\text { totalmente }\end{array}$ \\
\hline $\begin{array}{l}\text { O evento foi bem } \\
\text { organizado. }\end{array}$ & $\mathrm{O}$ & $\mathrm{O}$ & $\mathrm{O}$ & $\mathrm{O}$ & $\mathrm{O}$ \\
\hline $\begin{array}{l}\text { A comida era } \\
\text { saborosa. }\end{array}$ & $\mathrm{O}$ & 0 & $\mathrm{O}$ & $\mathrm{O}$ & 0 \\
\hline $\begin{array}{l}\text { A comida era } \\
\text { sofisticada. }\end{array}$ & $\mathrm{O}$ & 0 & $\mathrm{O}$ & $\mathrm{O}$ & 0 \\
\hline $\begin{array}{l}\text { A comida aparentava } \\
\text { obedecer aos } \\
\text { padrōes de higiene e } \\
\text { qualidade. }\end{array}$ & $\mathrm{O}$ & 0 & $\mathrm{O}$ & $\mathrm{O}$ & 0 \\
\hline $\begin{array}{l}\text { O ambiente era } \\
\text { animado. }\end{array}$ & $\mathrm{O}$ & $\mathrm{O}$ & $\mathrm{O}$ & $\mathrm{O}$ & 0 \\
\hline $\begin{array}{l}\text { A localização era } \\
\text { boa. }\end{array}$ & $\mathrm{O}$ & 0 & 0 & $\mathrm{O}$ & 0 \\
\hline
\end{tabular}


Näo houve

dificuldades para

estacionar no evento

$\mathrm{O}$

$\mathrm{O}$

O

O

O

Qual o seu sexo?

Masculino

Ferminino

Qual a sua idade?

Até 18 anos

Entre 19 e 25 anos

Entre 26 e 32 anos

Entre 33 e 39 anos

Acima de 39 anos

Qual a sua renda familiar mensal?

Até R\$ 2.000,00

Entre R\$ $2.000,00$ e R\$ 3.999,00

Entre R $\$ 4.000,00$ e R\$ 9.999,00

Entre R\$ $10.000,00$ e R $\$ 15.999,00$

Acima de R\$16.000,00

Muito obrigado!

Powered by Qualtrics 